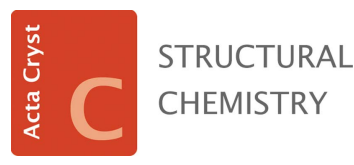

ISSN 2053-2296

Received 24 May 2019

Accepted 13 August 2019

Edited by P. Raithby, University of Bath, UK

Keywords: halogen bonds; experimental electron density; AIM analysis; crystal engineering; crystal structure; Raman spectroscopy.

CCDC reference: 1946856

Supporting information: this article has supporting information at journals.iucr.org/C

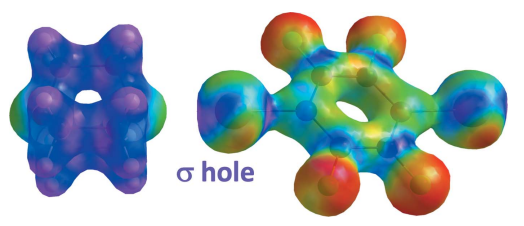

OPEN $\odot$ ACCESS

\section{The many flavours of halogen bonds - message from experimental electron density and Raman spectroscopy}

\author{
Ruimin Wang, ${ }^{\mathrm{a}, \mathrm{b}}$ Janine George, ${ }^{\mathrm{c}}$ Shannon Kimberly Potts, ${ }^{\mathrm{a}}$ Marius Kremer, ${ }^{\mathrm{a}}$ \\ Richard Dronskowski ${ }^{\mathrm{a}, \mathrm{d}, \mathrm{e}}$ and Ulli Englert ${ }^{\mathrm{a}, \mathrm{b}_{*}}$
}

\begin{abstract}
anstitute of Inorganic Chemistry, RWTH Aachen University, Landoltweg 1, Aachen 52056, Germany, ${ }^{\mathbf{b}}$ Institute of Molecular Science, Shanxi University, Taiyuan, Shanxi 030006, People's Republic of China, 'Institute of Condensed Matter and Nanosciences, Chemin des Étoiles 8/L7.03.01, Louvain-la-Neuve 1348, Belgium, dJlich-Aachen Research Alliance (JARA-HPC), RWTH Aachen University, Aachen 52056, Germany, and ${ }^{\mathbf{e}}$ Hoffmann Institute of Advanced Materials, Shenzhen Polytechnic, 7098 Liuxian Blvd, Shenzhen, People's Republic of China. *Correspondence e-mail: ullrich.englert@ac.rwth-aachen.de
\end{abstract}

Experimental electron-density studies based on high-resolution diffraction experiments allow halogen bonds between heavy halogens to be classified. The topological properties of the electron density in $\mathrm{Cl} \cdots \mathrm{Cl}$ contacts vary smoothly as a function of the interaction distance. The situation is less straightforward for halogen bonds between iodine and small electronegative nucleophiles, such as nitrogen or oxygen, where the electron density in the bond critical point does not simply increase for shorter distances. The number of successful chargedensity studies involving iodine is small, but at least individual examples for three cases have been observed. ( $a$ ) Very short halogen bonds between electronrich nucleophiles and heavy halogen atoms resemble three-centre-four-electron bonds, with a rather symmetric heavy halogen and without an appreciable $\sigma$ hole. (b) For a narrow intermediate range of halogen bonds, the asymmetric electronic situation for the heavy halogen with a pronounced $\sigma$ hole leads to rather low electron density in the $(3,-1)$ critical point of the halogen bond; the properties of this bond critical point cannot fully describe the nature of the associated interaction. (c) For longer and presumably weaker contacts, the electron density in the halogen bond critical point is only to a minor extent reduced by the presence of the $\sigma$ hole and hence may be higher than in the aforementioned case. In addition to the electron density and its derived properties, the halogen-carbon bond distance opposite to the $\sigma$ hole and the Raman frequency for the associated vibration emerge as alternative criteria to gauge the halogen-bond strength. We find exceptionally long $\mathrm{C}-\mathrm{I}$ distances for tetrafluorodiiodobenzene molecules in cocrystals with short halogen bonds and a significant red shift for their Raman vibrations.

\section{Introduction to halogen bonds}

The term 'halogen bond' denotes a short contact between a Lewis base $D$ and a heavy halogen $X(\mathrm{I}, \mathrm{Br}$ or $\mathrm{Cl})$ acting as electrophile (Hassel, 1970; Metrangolo \& Resnati, 2001); a schematic overview is provided in Fig. 1. More generally, halogen bonds may be understood as a special case of contacts in which a nucleophile approaches the electrophilic region of a neighbouring atom, so-called $\sigma$-hole interactions (Brinck et al., 1992, 1993; Politzer et al., 2017; George et al., 2014).

The nucleophilic atom $D$ usually corresponds to $\mathrm{N}, \mathrm{O}$ or $\mathrm{Cl}$, but other elements carrying a lone pair that is sufficiently exposed to the periphery and accessible to short contacts may also qualify as electron-density donors, e.g. sulfur (Şerb et al., 2015). In the most popular case in which the halogen $X$ is engaged in only one bond, its $\sigma$ hole forms opposite to it, 
implying a very pronounced directionality. The short contacts $X \cdots D$, which we nowadays address as halogen bonds, have not gone unnoticed by chemical crystallographers. We only mention two early examples here in which the authors explicitly point out short intermolecular distances. In the very first volume of Acta Crystallographica, E. Archer commented on the short intermolecular I . . O distances of $2.72 \AA$ between neighbouring $\mathrm{IO}_{2}$ groups in 1-chloro-4-iodylbenzene (Archer, 1948). The 1969 Nobel prize winner Hassel and co-workers (Borgen et al., 1962) reported $\mathrm{I} \cdots \mathrm{N}$ contacts of $2.93 \AA$ between neighbouring molecules of 3-iodopropiolonitrile, i.e. cyano- and iodo-substituted ethyne. In parallel with the idea of 'crystal engineering' (Desiraju, 1995), the number of published papers devoted to halogen bonds has markedly increased, from about 150 per year in the 1970s and 1980s to about 1000 per year in the last decade. A full account of the historic developments of the halogen bond and its applications in supramolecular chemistry is beyond the scope of this feature article and has been provided in a recent review (Cavallo et al., 2016).

An analysis of the Cambridge Structural Database (CSD; Groom et al., 2016) proves the existence of short and strongly directional contacts about heavy halogen atoms; intuition suggests two approaches to verify the interaction model described above. (a) Computational methods show the anisotropic charge distribution about $X$ and have often been used to justify experimental crystal structures, both for classical molecular crystals and biological structures (Wolters $e t$ al., 2014; Ford \& Ho, 2016). (b) In principle, X-ray diffraction is not limited to atomic resolution but may map the experimental electron density in more detail (Coppens, 1997). We here use high-resolution X-ray diffraction data to analyse and classify halogen bonds.

\section{Charge density of halogen bonds}

Not only $X$, the interaction partner with the $\sigma$ hole, but also the Lewis base $D$ (the halogen-bond acceptor) in Fig. 1 may be a halogen atom. Experimental charge-density studies on such short interhalogen contacts will be addressed in $\$ 2.1$, whereas $X \cdots D$ contacts between a heavy halogen and an $\mathrm{O}$ or $\mathrm{N}$ atom will be discussed in $\$ 2.2$.

\subsection{Results on interhalogen contacts}

Already in 1963, Sakurai et al. (1963) noted that $R-$ $X \cdots X-R$ contacts $(X=$ halogen atom) occur preferentially according to two distinct geometries. A geometric explanation for this directionality has become known as polar flattening (Nyburg \& Faerman, 1985); experimental charge-density

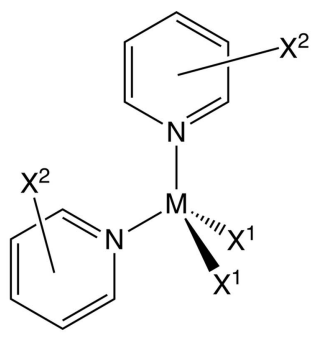

Neutral molecular complexes

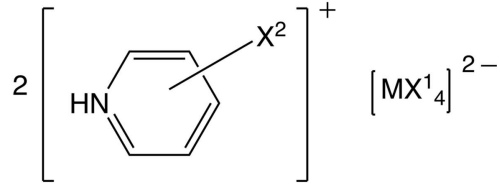

Ionic compounds with halides in the periphery
Figure 2

Two classes of compounds in which short interhalogen contacts are likely to occur.

studies are more recent. In order to better understand the protopypic structure of the diatomic heavy halides, Zhou and co-workers (Tsirelson et al., 1995) combined experimental data for crystalline $\mathrm{Cl}_{2}$ and the topology of the Laplacian for an isolated dichlorine molecule; Richard Bader was a coauthor of this article. A few years later, Boese and colleagues (Seppelt et al., 2004) communicated the crystal structure of chlorine fluoride, $\mathrm{ClF}$, which was unexpectedly dominated by short interchlorine contacts rather than by dipole interactions. This study of a short interhalogen contact represents an early example in which the analysis of the electron density was completely based on experimental data. In contrast to this early charge-density report, which dealt with $\mathrm{Cl} \cdots \mathrm{Cl}$ interactions shorter than $3.1 \AA$, experimental electron-density studies by the groups of Espinosa (Bui et al., 2009) and Guru Row (Hathwar et al., 2010) covered longer intermolecular $\mathrm{Cl} \cdots \mathrm{Cl}$ contacts. In order to induce shorter interchlorine distances in preferably stable crystalline solids and enlarge the experimental evidence on halogen bonds, we followed two approaches (Fig. 2).

(a) Complexes of divalent metal cations with halide ligands $X^{1}$ and halide $\left(X^{2}\right)$-substituted pyridines feature halogen atoms in their periphery and form molecular crystals in which short interhalogen contacts are very likely. (b) Halogen $\left(X^{2}\right)$ substituted pyridinium cations and tetrahalo $\left(X^{1}\right)$ metallate anions aggregate to salts, subtending hydrogen and halogen bonds. In both target classes of compounds, short interhalogen contacts occur with high frequency. Several among the latter ionic compounds formed crystals of only standard quality (Wang \& Englert, 2017) but others proved sufficient for an experimental electron-density study (Wang et al., 2017). Together with earlier results from our group (Wang et al., 2009, 2012, 2013) and those mentioned above (Bui et al., 2009; Hathwar et al., 2010), we can compile 18 examples of interchlorine contacts for which details of the experimental charge densities and properties of the bond critical points (bcps) are

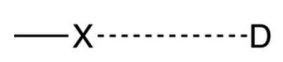

Figure 1

Halogen bonds and the $\sigma$-hole.

\section{$\mathrm{X}$ : heavy halogen $(\mathrm{Cl}, \mathrm{Br}, \mathrm{I})$ \\ D: nucleophile}

(e.g. halogen, $\mathrm{O}, \mathrm{N}, \mathrm{S})$

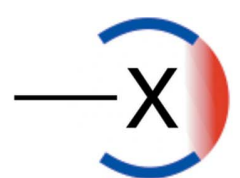

$\sigma$ hole

Lewis acidic

electrophilic region opposite to $\sigma$ bond 
available. In Fig. 3, the electron density in the $\mathrm{Cl}$. C Cl bcps has been plotted as a function of the interchlorine distance.

We can identify two regions in Fig. 3. (a) The electron density in the bcp increases with decreasing $\mathrm{Cl} \cdots \mathrm{Cl}$ distances shorter than $\mathrm{ca} 3.5 \AA$, the van der Waals distance (Bondi, 1964). This trend is not surprising because the short contacts are subtended by atoms of the same element type, i.e. similar electronegativities and atomic radii, and the bcp can be expected roughly at the mid-point between the participating atoms. (b) For interchlorine distances longer than $3.5 \AA$, the electron density in the bcp remains low and does not significantly vary as a function of the contact distance. In this region, the observed values for $\rho$ are most likely to be too small to allow conclusions concerning the strength and nature of the underlying intermolecular contacts (Kamiński et al., 2014).

\subsection{Results for I...N and I...O halogen bonds}

A very different situation is encountered for halogen bonds between the heavy halides and small electronegative Lewis basic atoms. In the context of experimental charge-density studies, Coppens (1977) coined the term 'suitability' for the ratio between valence and total electrons. With respect to this qualifier, short contacts to chlorine are the most attractive targets and the presence of iodine represents a particular challenge: crystals of very good quality and X-ray data of high redundancy will be required for a successful charge-density study. In terms of interaction strength, however, the sequence $\mathrm{I}>\mathrm{Br}>\mathrm{Cl}$ is accepted (Cavallo et al., 2016) and halogen bonds involving iodine can be associated with clearer polarization features and a more pronounced $\sigma$ hole. We note that the halogen atom in-between these extremes, bromine, does not represent an attractive compromise, at least if the diffraction experiments are conducted with Mo $K \alpha$ radiation: absorption represents a major challenge for accurate diffraction experiments, and the linear absorption coefficient for the element bromine is significantly higher than for its heavier congener. 1,2,4,5-Tetrafluoro-3,6-diiodobenzene (TFDIB) represents a

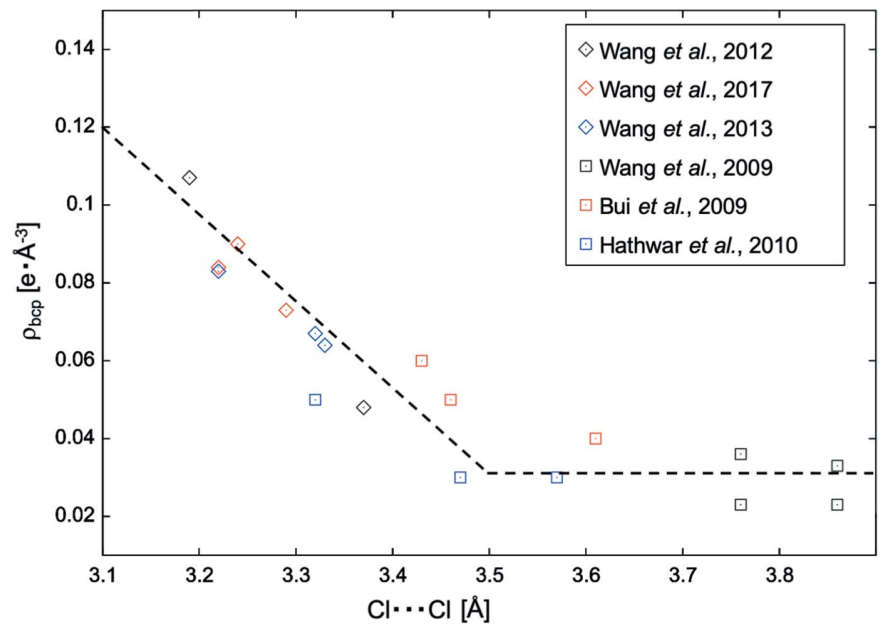

Figure 3

Graphical summary of electron density $\rho$ in the $\mathrm{Cl} \cdots \mathrm{Cl}$ bond critical point (bcp) versus intermolecular distance in short interchlorine contacts; dashed lines have been drawn to guide the eye and do not imply any fit.

particularly well-suited halogen-bond donor; it has been widely employed in crystal engineering. Bianchi and coworkers have performed high-resolution diffraction experiments to assess the experimental electron density in TFDIB

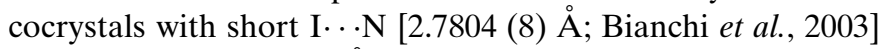
and I - . O [2.7253 (10) Аं; Bianchi et al., 2004] contacts. We have already mentioned that they find a slightly lower electron density in the shorter halogen bond. In the context of our systematic work on ditopic ligands (Kremer \& Englert, 2018), we have been able to investigate the charge density of a cocrystal between a substituted tris(acetylacetonato)aluminium(III) complex and TFDIB (Merkens et al., 2013); it involved I . . O distances of 3.026 (6) and 3.157 (2) A, and an I . . N contact of 2.833 (3) $\AA$.

In addition to these TFDIB adducts, we addressed a hypervalent iodoxy compound, the so-called Togni reagent I (Kieltsch et al., 2007). It is employed for the electrophilic transfer of a trifluoromethyl group and features inter-

\section{Co-crystal 1 trimolecular aggregate}

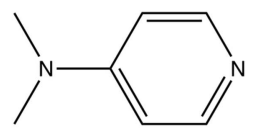

DMAP

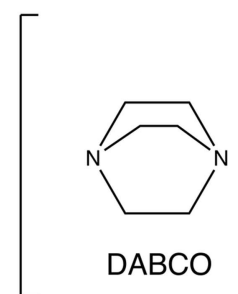

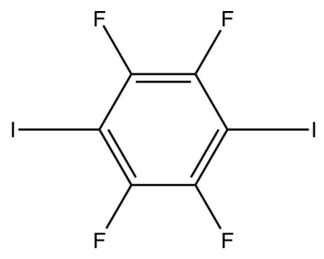

TFDIB

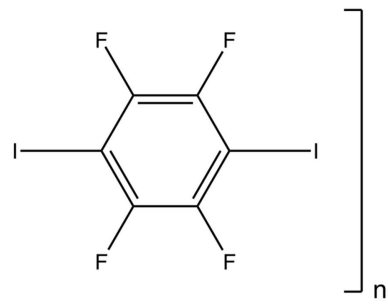

TFDIB

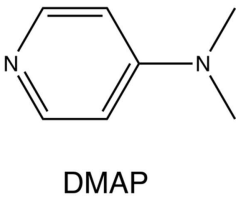

DMAP
Co-crystal 2 1D polymer

Figure 4

Target compounds with very short N …I contacts. 
Table 1

Properties of the electron density in the bcps of the $\mathrm{I} \cdots \mathrm{N}$ contacts and $\mathrm{I}-\mathrm{C}$ bonds in $\mathbf{1}$ and $\mathbf{2}$.

$R_{12}$ is the bond path, $d_{1}$ and $d_{2}$ its components, $\rho$ the electron density and $\nabla^{2}$ the Laplacian in the bcp. Results labelled as 'calc' were obtained from single-point calculations in experimentally established MM geometry.

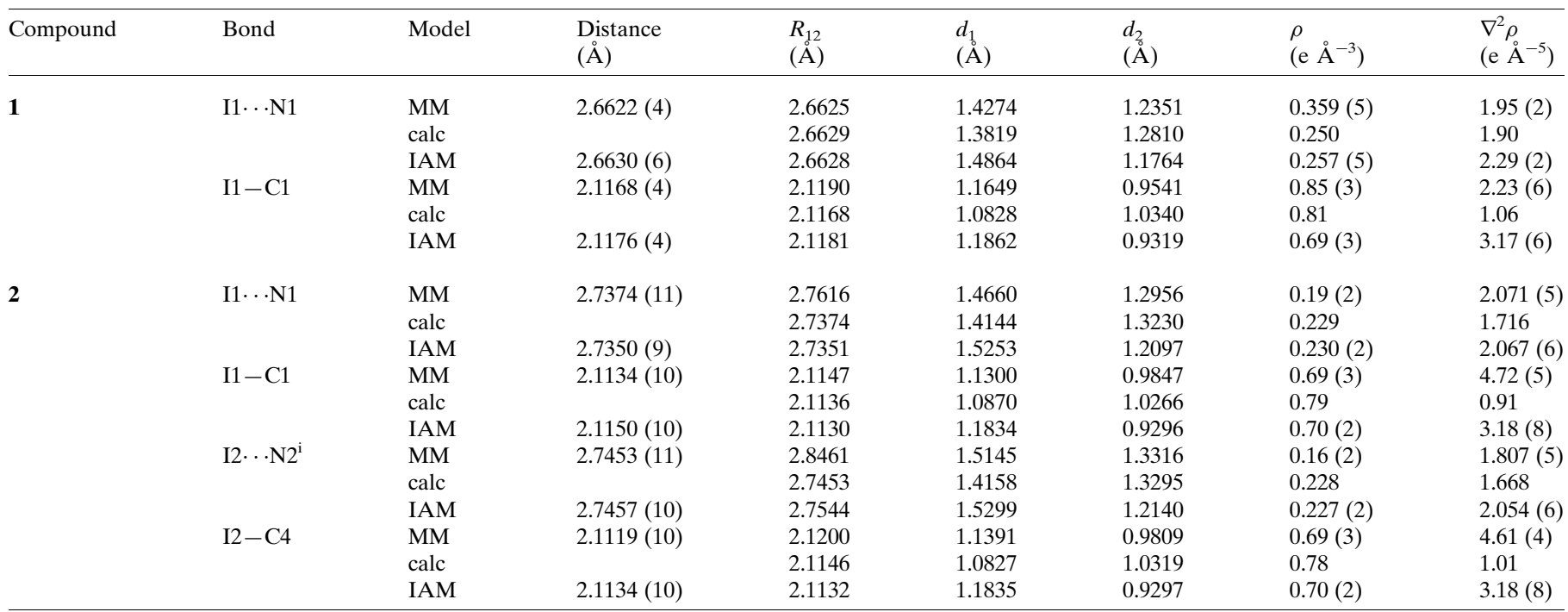

Symmetry code: (i) $x-2, y-1, z$.

molecular O . . I contacts of 2.9822 (9) $\AA$ in the solid state. Our high-resolution diffraction experiment (Wang et al., 2018b) confirmed predictions concerning the $\sigma$ hole (Kirshenboim \& Kozuch, 2016) and the approach of a nucleophile as an important step in the suggested mechanism (Sala et al., 2014, 2015). 70 years after Archer's observation (Archer, 1948) of short I . . O contacts between neighbouring iodoxy groups, our bona fide first experimental charge density for a hypervalent iodine derivative provided crystallographic evidence for the charge distribution about the halogen bond behind these interactions.

The above-mentioned charge-density studies revealed electron densities for the bcps in the $\mathrm{I} \cdots D(D=\mathrm{N}$ and $\mathrm{O})$ halogen bonds with $0.24>\rho_{\text {bcp }}>0.08$ e $\AA^{-3}$. We wanted to extend the contact range between TFDIB iodine and a suitable halogen-bond acceptor $D$, preferably Pearson-softer (Pearson, 1963) nitrogen, to significantly shorter distances and investigate the electron density associated with these halogen bonds. In order to reliably obtain well-ordered crystalline solids suitable for high-resolution X-ray diffraction, we screened the CSD and identified compounds $\mathbf{1}$ and $\mathbf{2}$ shown in Fig. 4 as the most promising candidates.

The cocrystal of TFDIB with 4-(dimethylamino)pyridine (DMAP), 1, was first structurally characterized by Karadakov, Bruce and co-workers (Roper et al., 2010). The composition of the solid is TFDIB(DMAP) $)_{2}$, with a trimolecular aggregate on a crystallographic centre of inversion. The I atom is engaged in a very short contact of 2.6622 (4) $\AA$ to the N atom of DMAP, a particularly nucleophilic pyridine derivative. The original authors did not only investigate short halogen bonds but also addressed the mechanochemical synthesis for this and related systems; we will come back to this aspect in \$2.5. The 1:1 cocrystal formed by TFDIB and diazabicyclooctane (DABCO), 2, features chains of alternating constituents, with two symmetry-independent $\mathrm{N} \cdots \mathrm{I}$ halogen bonds [2.7386 (11) and 2.7457 (10) $\AA$ ]. Its structure has been reported three times based on intensity data with standard resolution (Bolte, 2004; Cinčić et al., 2008; Syssa-Magalé et al., 2014). The results of our charge-density studies on the very short I $\cdots \mathrm{N}$ halogen bonds in $\mathbf{1}$ (Wang et al., 2018a) and $\mathbf{2}$ (this work) do not fit into a more general picture analogous to that encountered for interchlorine contacts (Fig. 3). Rather, the halogen bond in $\mathbf{1}$ is associated with a surprisingly high and those in $\mathbf{2}$ with unexpectedly low electron densities in the bcps, despite the comparable $\mathrm{I} \cdots \mathrm{N}$ distances. An explanation will be offered in the following section.

\subsection{Interpretation of very short I $\cdots D(D=N$ and $O)$ contacts}

Before we attempt to interpret the results of our experimental electron-density determinations for $\mathbf{1}$ and $\mathbf{2}$, we recall several essential differences between $\mathrm{Cl} \cdots \mathrm{Cl}$ and $\mathrm{I} \cdots D(D=$ $\mathrm{N}$ and $\mathrm{O}$ ) halogen bonds. In the latter contacts, iodine is the clearly less electronegative (IUPAC, 1997) and by far the larger (Cordero et al., 2008) partner. Bcps are usually located more closely to the less electronegative atom of an interaction (Gillespie \& Popelier, 2001). As a result, the bcp of such an asymmetric I $\cdots D$ interaction falls in the region of the charge depletion next to the larger and less electronegative partner iodine. In contrast to intuition, shorter I $\cdots D$ contacts may be associated with lower electron density in their bcp, and therefore this criterion does not necessarily qualify as a reliable tool to gauge the strength of a halogen bond. We recall the results of Bianchi et al. $(2003,2004)$ mentioned in the preceding section and we will come back to this aspect below. An unexpected trend for different structure models underlines the anticorrelation between electron density in the bcp of an asymmetric I $\cdots D$ halogen bond and the charge depletion on 
the I atom. The electron density in the bcp between partners of comparable atomic radius and electronegativity will usually come out higher for an advanced multipole model (MM) than for the conventional independent atom model (IAM); generally speaking, the latter does not qualify for modelling bonding electrons. This expected trend is encountered for covalent bonds between $\mathrm{C}, \mathrm{N}$ and $\mathrm{O}$ atoms and also for the $\mathrm{Cl} \cdots \mathrm{Cl}$ interhalogen contacts discussed in $\$ 2.1$. The opposite tendency may be observed for $\mathrm{I} \cdots D$ contacts with a very pronounced $\sigma$ hole: our cocrystal 2 provides an example for this behaviour. Stepwise expansion of the structure model from the IAM to higher multipoles emphasizes the $\sigma$ hole and concomitantly leads to a continuous decrease of the electron density in the bcp of the halogen bond; the corresponding compilation of bond critical properties as a function of the multipole expansion is provided in $\$ 5$ of the supporting information.

Fig. 5 visually compares the electrostatic potential (ESP) and the deformation density in our cocrystals $\mathbf{1}$ (Wang et al., $2018 a$ ) and 2 (this work), and allows for a discussion of the differences in their $\mathrm{I} \cdots \mathrm{N}$ bonds, despite their apparent chemical and geometric similarities.

The ESP for 2 (Fig. $5 b$ ) shows a distinct positive region (colour coded in magenta) on the I atom, opposite to its bond to carbon - the $\sigma$ hole! The neighbouring $\mathrm{N}$ atom approaches the heavy halogen with a much more negative region (green), thus underlining the strong electrostatic contribution to the halogen bond. Despite the similar I $\cdots \mathrm{N}$ distance, a $\sigma$ hole can hardly be perceived for $\mathbf{1}$ (Fig. $5 a$ ): neither the shape of the isosurface at the I atom nor the colour-coded potential show the clear features observed for 2 . Obvious common features of the ESPs for both compounds are the negative values for $\mathrm{F}$ and the positive values for $\mathrm{H}$ atoms. We note another difference between $\mathbf{1}$ and $\mathbf{2}$ : both the electron density, coded by the shape of the isosurface, and the colour-coded ESP for the I atoms in $\mathbf{1}$ indicate a rather balanced bonding situation towards its smaller neighbours $\mathrm{C}$ and $\mathrm{N}$, contrary to what one might expect for an I atom engaged in a covalent bond and a short contact. We will come back to this aspect below. The deformation densities in Fig. 5 (bottom) emphasize the differences between $\mathbf{1}$ and $\mathbf{2}$, and Table 1 summarizes the numerical results.

A surprisingly high electron density is found in the bcp of the short I $\cdots \mathrm{N}$ contact in $\mathbf{1}$ (Table 1 ). As expected for a strong interaction which is more reliably described by an aspherical model, its value increases from 0.257 (5) e $\AA^{-3}$ in the IAM to $0.359(5) \mathrm{e}^{-3}$ in the MM. We encountered comparable electron densities in coordinative bonds between $\mathrm{N}$ atoms and metal cations (Wang et al., 2009, 2012). Similar to the ESP for $\mathbf{1}$ (Fig. 5a), its deformation density in Fig. 5(c) shows a rather 'symmetric' environment for the I atom, with clearly visible polarization of both smaller neighbouring $\mathrm{C}$ and $\mathrm{N}$ atoms (a)
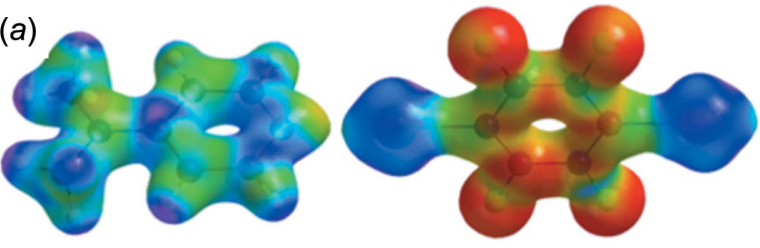

$-0.100$ (b)
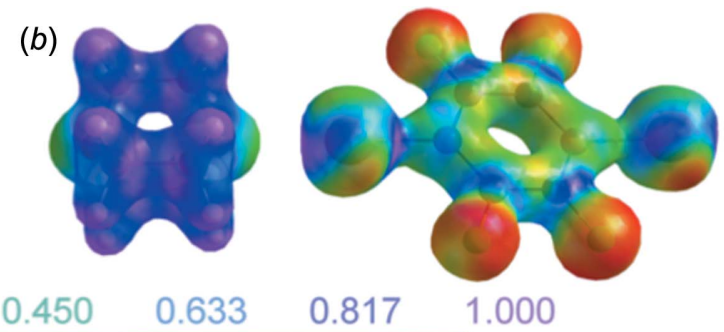
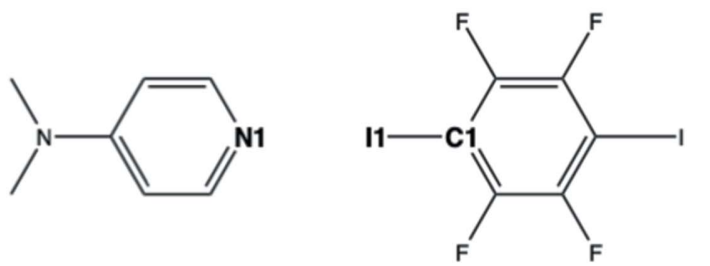

(c)
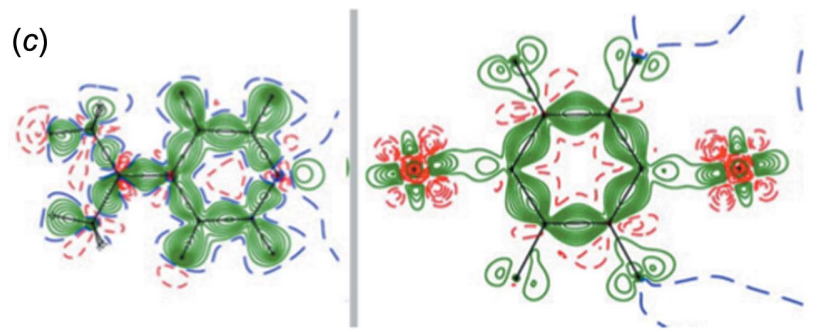

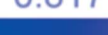

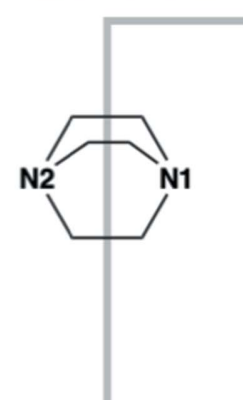

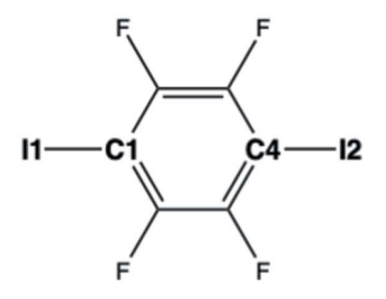

(d)

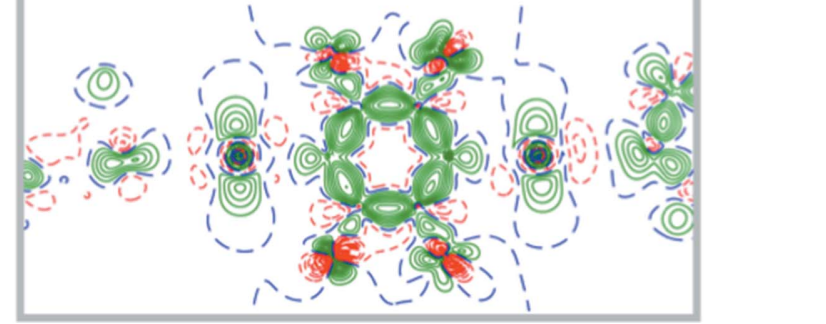

Figure 5

$(a) /(b)$ Electrostatic potential mapped on an isosurface of electron density $\rho=0.5$ e $\AA^{-3}$ (MoleCoolQt; Hübschle \& Dittrich, 2011) and (c)/(d) deformation density (contour lines are drawn at 0.1 e $\AA^{-3}$ ) for $\mathbf{1}$ and $\mathbf{2}$. In (c), the DMAP and TFDIB molecules are not completely coplanar; the grey line marks their intersection. In $(d)$, the grey box denotes the part of the chemical diagram for which the deformation density has been depicted. 
Table 2

Properties of the electron density in the bcps of the intermolecular contacts in 2.

$R_{12}$ is the bond path, $d_{1}$ its component with respect to the first atom, $\rho$ the electron density, $\nabla^{2}$ the Laplacian in the bcp, $G$ the kinetic, $V$ the potential and $E$ the total energy density. Results labelled as 'calc' were obtained from single-point calculations in experimentally established MM geometry.

\begin{tabular}{|c|c|c|c|c|c|c|c|c|c|c|}
\hline Bond & $\begin{array}{l}\text { Distance } \\
(\AA)\end{array}$ & $\begin{array}{l}R_{12} \\
(\AA)\end{array}$ & $\begin{array}{l}d_{1} \\
(\AA)\end{array}$ & $\stackrel{\rho}{\left(\mathrm{e} \AA^{-3}\right)}$ & $\begin{array}{l}\nabla^{2} \\
\left(\mathrm{e} \AA^{-5}\right)\end{array}$ & $\begin{array}{l}G \\
\text { (a.u.) }\end{array}$ & $\begin{array}{l}G / \rho \\
\text { (a.u.) }\end{array}$ & $\begin{array}{l}V \\
\text { (a.u.) }\end{array}$ & $|V| / G$ & $\begin{array}{l}E \\
\text { (a.u.) }\end{array}$ \\
\hline $\mathrm{I} 1 \cdots \mathrm{N} 1$ & $2.7374(11)$ & 2.7616 & 1.4660 & $0.19(2)$ & $2.071(5)$ & 0.0216 & 0.78 & -0.0217 & 1.00 & -0.0001 \\
\hline calc & & 2.7374 & 1.4144 & 0.229 & 1.716 & 0.0222 & 0.65 & -0.0267 & 1.20 & -0.0045 \\
\hline calc & & 2.7453 & 1.4158 & 0.228 & 1.668 & 0.00217 & 0.64 & -0.0261 & 1.20 & -0.0044 \\
\hline $\mathrm{F} 1 \cdots \mathrm{H} 15 A^{\mathrm{ii}}$ & 2.59 & 2.6176 & 1.4785 & $0.038(2)$ & $0.553(2)$ & 0.0043 & 0.77 & -0.0029 & 0.67 & 0.0014 \\
\hline
\end{tabular}

Symmetry codes: (i) $x-2, y-1, z$; (ii) $-x+2,-y+1,-z+2$; (iii) $x-1, y-1, z$; (iv) $-x+2,-y+1,-z+1$; (v) $-x,-y,-z+1$.

towards the heavy halogen. From this point of view, the short contact between TFDIB iodine and DMAP nitrogen is more reminiscent of a three-centre-four-electron bond than of a $\sigma$ hole interaction. In contrast, the I atoms in $\mathbf{2}$ exhibit the expected charge depletions (Fig. $5 d$ and Table 1) in the direction of their close $\mathrm{N}$-atom neighbours. Fig. $5(d)$ shows zero contour levels (dashed blue lines) in the deformation density of 2 . The bcps between I and $\mathrm{N}$ fall in the negative region - the deformation density picture indicates a low electron density in these points, even without resorting to the Laplacian! The $\sigma$-hole geometry becomes more visible in the MM: the $\mathrm{I} \cdots \mathrm{N}$ bcps move towards the heavy halogen and their electron density decreases when passing from the IAM to the MM. The pronounced charge depletion associated with the very short $\mathrm{I} \cdots \mathrm{N}$ contact in $\mathbf{2}$ and the ratio of the atomic radii discussed above leads to electron densities in the bcps of the halogen bonds which are smaller than in the case of the longer I $\cdots \mathrm{N}$ or I $\cdots \mathrm{O}$ separations discussed in $\$ 2.2$. For one of the two symmetrically independent short contacts [I $\cdots \mathrm{N} 2{ }^{\mathrm{i}}$; symmetry code: (i) $x-2, y-1, z]$ in $\mathbf{2}$ the bond path is significantly longer than the interatomic distance (Table 1), and the associated bcp could not be located routinely. More detailed information is given in the Experimental section and in the supporting information. The gradient vector plots and the Laplacian of the electron density depicted in Fig. 6 confirm the presence of a $\sigma$ hole on both I atoms in $\mathbf{2}$.

How do the results of the single-point calculations in Table 1 compare to the experimentally derived electron density? The covalent $\mathrm{C}-\mathrm{I}$ bonds are satisfactorily reproduced but the unusual I . . N interactions can be expected to be challenges for theory. Indeed, neither the very strong and more 'symmetric' $\mathrm{I} \cdots \mathrm{N}$ contacts in $\mathbf{1}$ nor the very short halogen bonds in $\mathbf{2}$ are well described: electron densities in the bcps of the former are underestimated and of the latter are overestimated!

High-resolution X-ray diffraction experiments followed by analysis of the derived electron density can provide a very reliable insight into bonding but is, of course, not always feasible. Fortunately, we may offer a geometry-based criterion, which at least for these TFDIB derivatives may help in the interpretation and which we first discovered in our detailed analysis of $\mathbf{1}$. We recalled the above statement 'more reminiscent of a three-centre-four-electron bond': a stronger I $\cdots D$
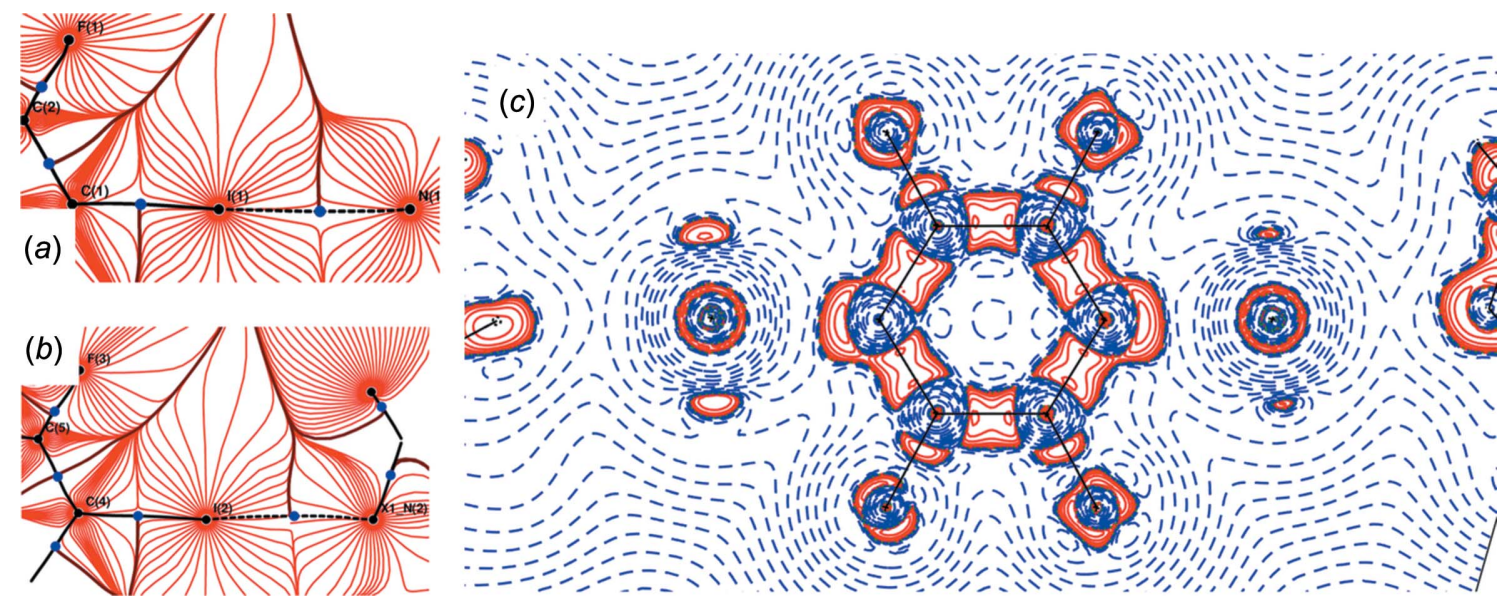

Figure 6

Gradient vector field of the electron density for $(a) \mathrm{I} 1 \cdots \mathrm{N} 1$ and $(b) \mathrm{I} 2 \cdots \mathrm{N} 2{ }^{\mathrm{i}}$ in $\mathbf{2}$; bond paths are shown as black lines and bcps as dark-blue solid circles. (c) Laplacian of the electron density for the TFDIB molecule in 2 , with positive values in blue, negative values in red and contours at $\pm 2^{n} \times 10^{-3} \mathrm{e} \AA^{-5}$ $(0 \leq n \leq 20)$. 
interaction implies weakening of the $\sigma$ bond and a longer $\mathrm{I}-\mathrm{C}$ distance. Fig. 7 shows that this effect is indeed observed and significant.

Both $\mathbf{1}$ and 2, despite their very different characteristics in the short intermolecular I $\cdots \mathrm{N}$ contacts, show very long and presumably weak $\mathrm{I}-\mathrm{C}$ bonds opposite to the short contacts. In contrast, the $\mathrm{I} \cdots D$ halogen bonds in the remaining compounds investigated by Bianchi et al. ['c' in Fig. 7 (Bianchi et al., 2003) and 'e' in Fig. 7 (Bianchi et al., 2004)] and our group ('d' in Fig. 7; Merkens et al., 2013) are associated with unexceptional $\mathrm{I}-\mathrm{C}$ distances, close to the database average. It is tempting to search the CSD for a more general anticorrelation between short $\mathrm{I} \cdots D$ contacts and long $\mathrm{I}-\mathrm{C}$ bonds but the result is less conclusive than one might intuitively expect. Halogen bonds with their strong electrostatic contribution cover a wide range of distances; contacts between iodine and a small electronegative nucleophile, such as nitrogen or oxygen, may be as short as in $\mathbf{1}$, i.e. in the range of 2.6 $\AA$. The upper limit is largely a matter of taste but will often be associated with the sum of the van der Waals radii and will at least extend to 3.3 or $3.4 \AA$. The covalent bond between $\mathrm{C}$ and $\mathrm{I}$ in the TFDIB molecule is largely dominated by orbital overlap and ranges between 2.07 and $2.12 \AA$. In either case, a realistic error bar for structures derived from diffraction data at standard resolution is about equally high and amounts to $c a$ $0.01 \AA$. The earlier database entries for our compound 2 (CSD refcodes ISIHUN (Bolte, 2004) and ISIHUN01 (Cinčić et al., 2008)] provide an instructive proof for this statement: two lowtemperature data collections (100 and $180 \mathrm{~K}$ ) and refinements were conducted independently and resulted in $\mathrm{I}-\mathrm{C}$ bond lengths between 2.110 and $2.121 \AA$. In summary, correlation between a first variable of $c a 0.7 \pm 0.01 \AA$ and a second of $c a$ $0.05 \pm 0.01 \AA$ is attempted, and the result is necessarily noisy. The few charge-density studies with their obviously higher resolutions can, of course, be expected to be more precise than

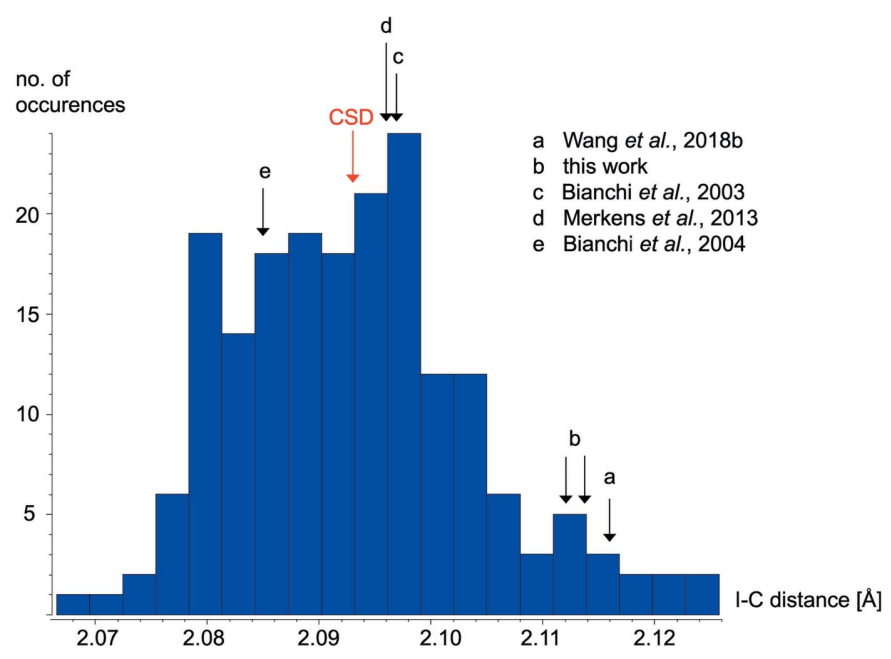

Figure 7

Histogram of $\mathrm{I}-\mathrm{C}$ distances from TFDIB structures in the CSD (Groom et al., 2016; error-free structures, no disorder, $T \leq 150 \mathrm{~K}$ ). Selected data for TFDIB cocrystals with short $\mathrm{C}-\mathrm{I} \cdots D$ contacts have been included (see text). (For 'a-d', $D=\mathrm{N}$ and for 'e', $D=\mathrm{O}$; CSD indicates the CSD average.)

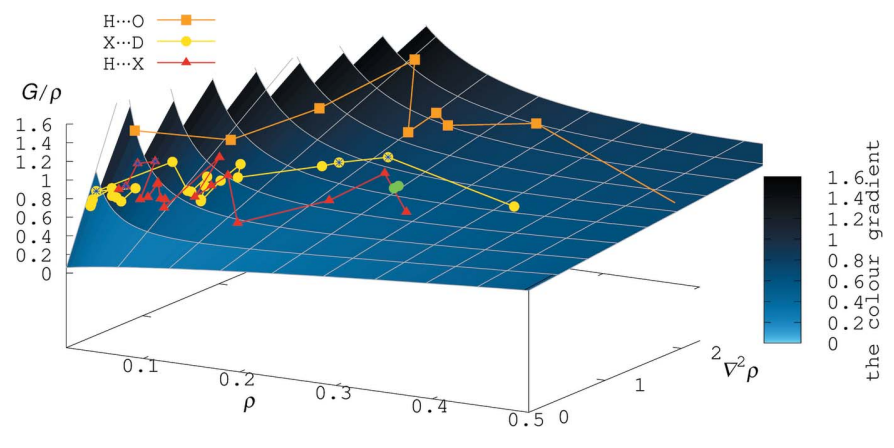

Figure 8

Ratio $G / \rho$ as a function of the electron density $\rho$ and its Laplacian; all quantities refer to the bcp. Experimental results for halogen bonds are shown in yellow, for $\mathrm{H} \cdots X$ in red and for $\mathrm{H} \cdots \mathrm{O}$ in orange. The yellow circles marked with an asterisk $(*)$ represent the experimental and the green circles the theoretically calculated values for 2 .

the overall database screening. A (still rather poor) anticorrelation can be perceived when the search is limited to the strongest halogen bonds $(\mathrm{I} \cdots \mathrm{N}<2.8 \AA$ ) for which a significant effect on $\mathrm{I}-\mathrm{C}$ can be expected. The corresponding scatterplot is available in the supporting information.

The difference between $\mathbf{1}$ and $\mathbf{2}$ is also reflected in the electron densities in the I-C bcps (Table 1). In $\mathbf{1}, \rho_{\mathrm{bcp}}$ for $\mathrm{I} \cdots \mathrm{N}$ and $\mathrm{I}-\mathrm{C}$ show the same trend and increase, as is to be expected, when the IAM is replaced by the aspherical MM. In contrast, the values for $\rho_{\text {bcp }}$ of $\mathrm{I}-\mathrm{C}$ in $\mathbf{2}$ are hardly affected by the model and are in close agreement with earlier results (Bianchi et al., 2003, 2004; Merkens et al., 2013).

\subsection{Energy density considerations}

In addition to the electron density $\rho$ and its Laplacian, energy densities have been used to categorize secondary interactions. The kinetic energy density $G$ and the ratio between kinetic energy density and electron density, $G / \rho$ in the bcp, were derived as suggested by Abramov (1997), and the potential energy density $V$ was obtained according to the local virial theorem (Espinosa et al., 1998, 1999). G/ $\rho$ has proven useful for classifying hydrogen bonds (Şerb et al., 2011) but does not represent a very sensitive qualifier for halogen bonds. More successful was an alternative criterion: the total energy density $E$, the difference between the (positive) kinetic energy density $G$ and the (negative) potential energy density $V$, assumes negative values for covalent bonds (Cremer \& Kraka, 1984) and only for the shortest $\mathrm{Cl} \cdots \mathrm{Cl}$ interactions (Wang et al., 2017). In line with this argument, an unambiguously negative value for $E$ is calculated for the short $\mathrm{I} \cdots \mathrm{N}$ contact in 1. Espinosa et al. (2002) have suggested the ratio $|V| /$ $G$ to distinguish between pure closed-shell and incipient shared-shell interactions. With respect to this criterion, the short intermolecular contact in $\mathbf{1}$ is characterized by $|V| / G=$ 1.42 (Wang et al., 2018a) and falls in the regime of shared interactions. When we apply the same qualifiers $E$ and $|V| / G$ to a significantly longer but still relevant halogen bond, e.g. the short I $\cdots$ O contact in the hypervalent Togni reagent (Wang et $a l ., 2018 b)$, a slightly positive total energy density $E$ and $|V| / G=$ 


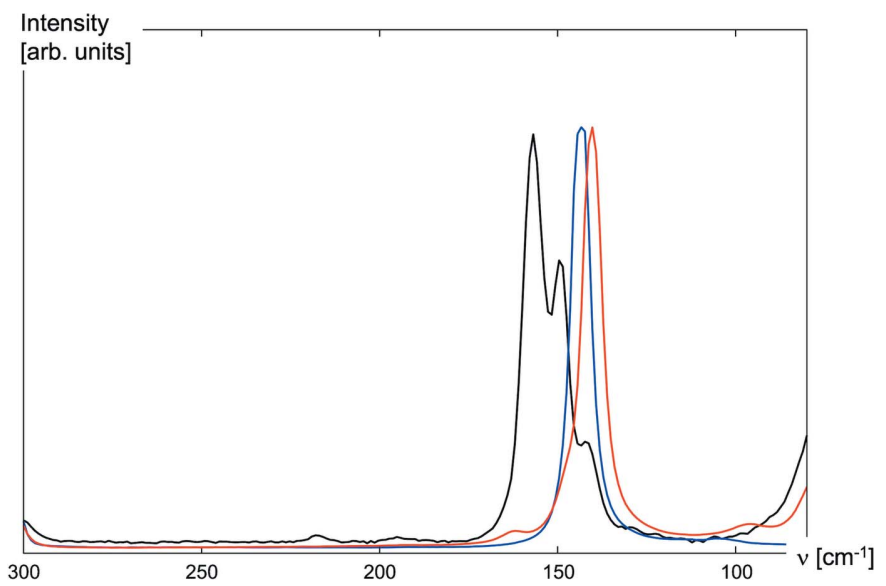

Figure 9

Raman spectra for TFDIB (black) and its cocrystals $\mathbf{1}$ (red) and $\mathbf{2}$ (blue) in the frequency range $300-80 \mathrm{~cm}^{-1}$.

0.86 are obtained, indicating a closed-shell interaction as expected. In summary, both criteria are promising and distinguish between presumably incipient shared- and closedshell interactions. Our compound 2, with its unexpectedly low electron density in the bcps of the short I . . N contacts, does remain ambiguous, again, with respect to these criteria. When we focus on experiment, the total energy densities $E$ are close to 0 , similar to what is seen for much longer $I \cdots D$ contacts; the ratio $|V| / G$ adopts values close to 1.0 (Table 2), i.e. in-between closed and shared interactions.

The results of the single-point calculation suggest a different interpretation, with significantly negative values for $E$ and $|V| / G=1.20$; both qualifiers seem to indicate a more shared interaction. As a result of the very pronounced $\sigma$ hole in close vicinity to the $\mathrm{I} \cdots \mathrm{N}$ bcp in $2, \rho_{\text {bcp }}$ in these contacts is much lower than expected and properties derived from the electron density are equally affected. We have summarized different properties in the bcps for halogen bonds and other classes of intermolecular contacts in Fig. 8. This graph was originally suggested based on data compiled in our 2017 article (Wang et al., 2017) and later extended (Wang et al., 2018a) to cover the short I $\cdots \mathrm{N}$ contact in $\mathbf{1}$; it relates relates $G / \rho$ with the electron density $\rho$ and its Laplacian $\nabla^{2}$. High values for $G /$
Table 3

Weakening of $\mathrm{I}-\mathrm{C}$ by strong halogen bonds: experimentally observed versus calculated Raman frequencies and Integrated Crystal Orbital Hamilton Population (ICOHP) for TFDIB, 1 and 2.

\begin{tabular}{llll}
\hline compound & TFDIB & $\mathbf{1}$ & $\mathbf{2}$ \\
\hline$\nu_{\exp }\left(\mathrm{cm}^{-1}\right)$ & 157 & 140 & 143 \\
$\nu_{\text {calc }}\left(\mathrm{cm}^{-1}\right)$ & 158 & 138 & 142 \\
ICOHP I $\cdots \mathrm{N}(\mathrm{eV})$ & & -1.1 & -0.8 \\
ICOHP I-C $(\mathrm{eV})$ & -5.7 & -4.8 & -4.9 \\
\hline
\end{tabular}

$\rho$ are only observed for hydrogen bonds to oxygen (orangecoloured data points in Fig. 8). Halogen bonds (yellow data points) are less sensitive with respect to this qualifier and better categorized with the help of $E$ or $|V| / G$; they do cover, however, an impressive range of electron density in their $(3,-1)$ critical points. In $\mathbf{2}$ and, most likely, in related compounds with very short $\sigma$-hole contacts, every classification exclusively based on bcp properties is associated with a large uncertainty: the discrepancy between experimentally derived [yellow circles marked with an asterisk (*)] and theoretically calculated (green circles) qualifiers is reflected in the different location of the highlighted data points in Fig. 8.

\subsection{Raman spectroscopy as a diagnostic tool for short halogen bonds}

Diffraction data at standard resolution qualify for discussions of crystal engineering, being sufficient to obtain atomic coordinates and derive interatomic distances and angles. Considerations concerning the electron density and the nature of bonds and short contacts require high-resolution data. In the preceding sections, we suggested a link between halogenbond strength and (precise) molecular geometry. So far, our discussion about halogen bonding has relied on the results of diffraction experiments. Based on the results for TFDIB and its cocrystals $\mathbf{1}$ and $\mathbf{2}$, we suggest Raman spectroscopy as a straightforward alternative tool to probe short intermolecular I . . N contacts. On the one hand, intense Raman signals may be expected for modes to which the highly polarizable I atoms contribute. On the other hand, the results discussed in $\$ 2.3$ suggest that short $\mathrm{I} \cdots \mathrm{N}$ interactions lead to longer and

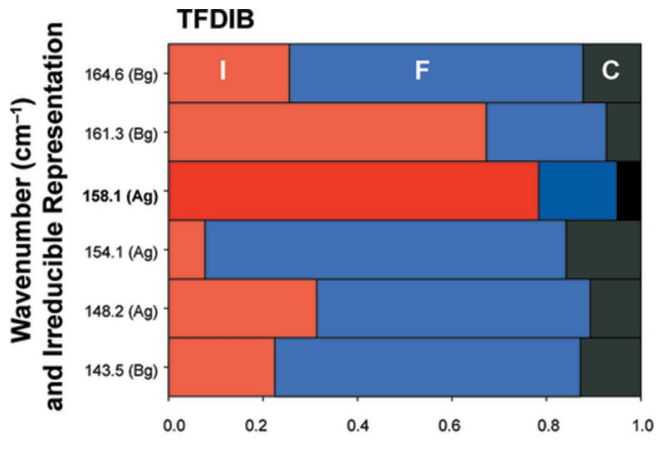

Figure 10

Contributions of atoms to Raman-active phonon modes in the range from 100 to $200 \mathrm{~cm}^{-1}$ for TFDIB and cocrystals $\mathbf{1}$ and $\mathbf{2}$. The modes with the most significant contribution of iodine in this range are highlighted in bold for the labels and more intense colours for the bar chart. These highlighted wavenumbers have been included in Table 3 and closely match the experimental values depicted in Fig. 9. 
presumably weaker $\mathrm{I}-\mathrm{C}$ bonds, and a shift of the corresponding absorption to lower frequencies may be perceived as an indicator for halogen bonds. Fig. 9 shows the Raman spectra for TFDIB and its cocrystals $\mathbf{1}$ and $\mathbf{2}$ in the frequency range in which we expect $\mathrm{C}-\mathrm{I}$ vibrations.

Our interpretation of the observed red shift in the presence of I . . N halogen bonds relies on the good agreement between observed and calculated spectra compiled in Table 3.

The results of the phonon calculations in the range of the C-I bonds are summarized in Fig. 10.

Furthermore, the results from the Raman spectra are in good agreement with results from bonding analysis. Integrated Crystal Orbital Hamilton Population (ICOHP) values have been used successfully to evaluate the strengths of hydrogen and tetrel bonds within crystal structures (Deringer et al., 2014, 2017; George \& Dronskowski, 2017). The ICOHP for the $\mathrm{I} \cdots \mathrm{N}$ interaction in the cocrystals $\mathbf{1}$ and $\mathbf{2}$, and for the $\mathrm{C}-\mathrm{I}$ bond in all three compounds TFDIB, $\mathbf{1}$ and $\mathbf{2}$ have been included in Table 3 and match the red shift in the Raman spectra. ICOHP values for $\mathrm{I}-\mathrm{C}$ are significantly smaller for the cocrystals and indicate weakening of the covalent $\mathrm{I}-\mathrm{C}$ bond as a result of the short halogen bonds in the cocrystals.

We already mentioned that Karadakov, Bruce and coworkers (Roper et al., 2010) could synthesize a series of halogen-bonded cocrystals by grinding. In this light of mechanochemistry, Raman spectroscopy as an alternative tool to analyse halogen bonding without the necessity of crystallization and single-crystal diffraction gains significant importance.

\section{Experimental}

\subsection{Synthesis and crystallization}

High-quality single crystals of $\mathbf{2}$ were obtained from an equimolar solution of the components as first described by Cinčić et al. (2008); matching elemental analysis and powder patterns were obtained. Cocrystal 2 may also be obtained mechanically by grinding the constituents (Cinčić et al., 2008); even when the constituents are only mixed as solid powders without grinding, partial formation of cocrystalline $\mathbf{2}$ is observed. The corresponding powder patterns are provided in the supporting information.

\subsection{Single-crystal X-ray diffraction}

Intensity data for $\mathbf{2}$ were collected at $100 \mathrm{~K}$ on a Stoe Stadivari goniometer equipped with a Dectris Pilatus $200 \mathrm{~K}$ detector using Mo $K \alpha$ radiation $(\lambda=0.71073 \AA$ ). The radiation source was a XENOCS microsource equipped with multilayer optics. An Oxford Cryosystems 700 controller was used to ensure temperature stability during data collection. The intensity data were processed with $X$-AREA (Stoe \& Cie, 2017). Direction-dependent scaling in the subprogram $L A N A$ and its relationship to the well-established SORTAV program (Blessing, 1995) have been described by Koziskova et al. (2016). Crystal data and information concerning data collection are compiled in Table 4 . The independent atom refinement was performed by full-matrix least squares on $F^{2}$
Table 4

Experimental details for $\mathbf{2}$.

\begin{tabular}{|c|c|}
\hline \multicolumn{2}{|l|}{ Crystal data } \\
\hline Chemical formula & $\mathrm{C}_{6} \mathrm{H}_{12} \mathrm{~N}_{2} \cdot \mathrm{C}_{6} \mathrm{~F}_{4} \mathrm{I}_{2}$ \\
\hline$M_{\mathrm{r}}$ & 514.04 \\
\hline Crystal system, space group & Triclinic, $P \overline{1}$ \\
\hline Temperature (K) & 100 \\
\hline$a, b, c(\AA)$ & $\begin{array}{l}6.77971(9), 10.82624(17) \\
\quad 11.36217(17)\end{array}$ \\
\hline$\alpha, \beta, \gamma\left({ }^{\circ}\right)$ & $\begin{array}{l}107.3260(12), 92.9637(12) \\
104.7718(12)\end{array}$ \\
\hline$V\left(\AA^{3}\right)$ & $762.42(2)$ \\
\hline$Z$ & 2 \\
\hline Radiation type & Мо $K \alpha$ \\
\hline$\mu\left(\mathrm{mm}^{-1}\right)$ & 4.16 \\
\hline Crystal size $(\mathrm{mm})$ & $0.27 \times 0.07 \times 0.03$ \\
\hline \multicolumn{2}{|l|}{ Data collection } \\
\hline Diffractometer & $\begin{array}{l}\text { Stoe \& Cie Stadivari goniometer } \\
\text { with a Pilatus } 200 \mathrm{~K} \text { area } \\
\text { detector }\end{array}$ \\
\hline Absorption correction & $\begin{array}{l}\text { Multi-scan ( } X \text {-AREA; Stoe \& Cie, } \\
\text { 2017) }\end{array}$ \\
\hline$T_{\min }, T_{\max }$ & $0.245,0.691$ \\
\hline $\begin{array}{l}\text { No. of measured, independent and } \\
\text { observed }[I>2 \sigma(I)] \text { reflections }\end{array}$ & $143675,12807,9751$ \\
\hline$R_{\text {int }}$ & 0.049 \\
\hline$(\sin \theta / \lambda)_{\max }\left(\AA^{-1}\right)$ & 1.004 \\
\hline \multicolumn{2}{|l|}{ Refinement (IAM) } \\
\hline$R\left[F^{2}>2 \sigma\left(F^{2}\right)\right], w R\left(F^{2}\right), S$ & $0.018,0.034,1.00$ \\
\hline No. of reflections & 12807 \\
\hline No. of parameters & 181 \\
\hline$\Delta \rho_{\max }, \Delta \rho_{\min }\left(\mathrm{e} \AA^{-3}\right)$ & $0.80,-1.16$ \\
\hline \multicolumn{2}{|l|}{ Refinement (MM) } \\
\hline$R\left[F^{2}>2 \sigma\left(F^{2}\right)\right], w R\left(F^{2}\right), S$ & $0.016,0.022,0.99$ \\
\hline No. of reflections & 12807 \\
\hline No. of parameters & 464 \\
\hline$\Delta \rho_{\max }, \Delta \rho_{\min }\left(\mathrm{e} \AA^{-3}\right)$ & $0.64,-0.64$ \\
\hline
\end{tabular}

Computer programs: X-AREA (Stoe \& Cie, 2017), SHELXS97 (Sheldrick, 2008), SHELXL2018 (Sheldrick, 2015) and PLATON (Spek, 2009).

(Sheldrick, 2015). $\mathrm{H}$ atoms were treated as riding, with $\mathrm{C}-\mathrm{H}=$ $0.99 \AA$ and $U_{\text {iso }}(\mathrm{H})=1.2 U_{\text {eq }}(\mathrm{C})$.

\subsection{Multipole refinement and AIM analysis}

The final IAM served as the starting point for the multipole model (MM). Equivalent reflections were averaged with the help of the program MERGEHKLF5 (Schreurs, 2004). Multipole refinements on $F^{2}$ based on the Hansen-Coppens formalism for aspheric atomic density expansion (Hansen \& Coppens, 1978) were carried out with the program XD2006; the VM data bank based on unpublished work by Volkov and Macchi was used (Volkov et al., 2006). Refinement was conducted with all intensity data. The refined anisotropic displacement parameters were in agreement with the rigid bond postulate (Hirshfeld, 1976). Refinement of anharmonic displacement parameters, more specifically third- and fourthorder Gram-Charlier coefficients for iodine and third-order coefficients for F atoms (Sørensen et al., 2003), was attempted but not further pursued because the resulting structure models were associated with slightly more favourable agreement factors but higher residual electron densities at the expense of significantly more refined variables. The final successful 
multipole refinement converged for low and symmetric residual electron-density maxima and minima (Table 4, and Fig. S12 in the supporting information). The remaining features in the final difference Fourier map are located close to the I atom and indicate limitations of the atom-centred multipole model restricted to the valence shell rather than anharmonic motion or inconsistencies with the intensity data. This interpretation is corroborated by the fractal dimension, probability distribution histograms and normal probability plots provided in the supporting information (Figs. S9-S11). The final MM comprised multipoles up to hexadecapoles for non- $\mathrm{H}$ atoms and up to bond-directed dipoles for the $\mathrm{H}$ atoms. The space group did not require any symmetry constraint on multipoles; chemical constraints were introduced for $\mathrm{C}$ and $\mathrm{H}$ atoms, i.e. all methylene $\mathrm{C}$ atoms, the I-substituted $\mathrm{C}$ atoms in the TFDIB molecule and the F-substituted $\mathrm{C}$ atoms in the TFDIB molecule, and all $\mathrm{H}$ atoms in the DABCO molecule were treated as chemically equivalent (Table S4 in the supporting information). Contraction parameters $\kappa$ for non- $\mathrm{H}$ atoms were refined freely; $\kappa$ for $\mathrm{H}$ was constrained to 1.2 and $\kappa^{\prime}$ for all atoms were kept unrefined at the default values of 1.0 for non- $\mathrm{H}$ and 1.2 for $\mathrm{H}$ atoms. In the $\mathrm{MM}, \mathrm{C}-\mathrm{H}$ distances were constrained to $1.09 \AA$. The topology of the experimental electron density was analyzed according to Bader's AIM theory (Bader, 1990); the search for critical points was conducted with XDPROP (as supplied with XD2006; Volkov et al., 2006) and TOPXD (Volkov et al., 2000). For one of the short contacts in 2 [I $2 \cdots \mathrm{N} 2^{\mathrm{i}}$; symmetry code: (i) $x-2, y-1$, $z$ ], both programs failed to locate the bcp by the usual approach based on short contacts between atom pairs ( $\$ 5$ of the supporting information), although a graphical interpolation indicated relevant electron density along the interatomic path. A search in the asymmetric unit of $\mathbf{2}$ with TOPXD was successful and gave the same $\rho_{\text {bcp }}$ as the graphical estimate.

\subsection{Raman spectroscopy}

Raman spectra were obtained with a Horiba LABRAM HR instrument equipped with a $633 \mathrm{~nm} \mathrm{HeNe}$ excitation laser.

\subsection{Computational methods}

In order to complement the experimental electron-density results with a theoretical description of the strongest intermolecular interactions, calculations were performed on a three-molecule DMAP-TFDIB-DMAP aggregate in the case of $\mathbf{1}$ and on a four-molecule TFDIB-DABCO-TFDIB$\mathrm{DABCO}$ aggregate in the case of $\mathbf{2}$. The experimentally observed geometries were used for single-point calculations, which were performed with GAUSSIAN09 (Frisch et al., 2009) at the density functional theory (DFT) level with the B3LYP functional (Becke, 1993; Lee et al., 1998; Vosko et al., 1980; Stephens et al., 1994) and the MIDIX basis set (Thompson et al., 2001). The wavefunctions obtained through these calculations were used for the topological analysis of the resulting electron density with the help of the program AIMAll (Keith, 2017) Figs. S16 and S17 in the supporting information show these results for $\mathbf{2}$, the compound for which the experimental electron density is reported for the first time in this work.

Forces for all phonon calculations and the preceding structural optimizations were calculated with dispersion-corrected DFT as implemented in VASP (Kresse \& Hafner, 1993, 1994; Kresse \& Furthmüller, 1996), with strict convergence criteria of $\Delta E<10^{-7}\left(10^{-5}\right) \mathrm{eV}$ per cell for electronic (structural) optimizations, respectively. In contrast to the aforementioned calculations based on molecular aggregates, periodic boundary conditions were used for the calculations. We used the projector augmented-wave method (Blöchl, 1994; Kresse \& Joubert, 1999), with a plane wave cut-off of $500 \mathrm{eV}$, and the Perdew-Burke-Ernzerhof (PBE) functional (Perdew et al., 1996). In addition to the PBE functional, we also used the 'D3' correction of Grimme and co-workers, together with Becke-Johnson damping (Grimme et al., 2010, 2011). Instead of the traditional damping parameters, as fitted by Grimme and co-workers, we used those suggested by the group of Sherrill $\left(s_{6}=1.00, s_{8}=0.358940, \alpha_{1}=0.012092\right.$ and $\alpha_{2}=$ 5.938951) (Smith et al., 2016). In previous work, this method was successfully applied to describe the thermal expansion of the halogen-bond-containing compound pentachloropyridine (George et al., 2017). The prediction of thermal expansion with the help of the quasi-harmonic approximation relies very much on a good description of the underlying frequencies calculated within the harmonic approximation.

To perform the phonon calculations, we used the finite displacement method as implemented in Phonopy (https:// atztogo.github.io/phonopy/), with a displacement of $0.01 \AA$ and a $3 \times 2 \times 4$ supercell for TFDIB, a $3 \times 2 \times 2$ supercell for TFDIB.DABCO, $\mathbf{1}$, and a $2 \times 1 \times 2$ supercell for TFDIB-DMAP, 2 (Togo et al., 2008; Togo \& Tanaka, 2015). Furthermore, the force calculations were performed at the $\Gamma$-point. The irreducible representations of the phonon modes at the $\Gamma$-point were also determined with the help of Phonopy. The atomic contributions to each phonon mode were calculated and visualized with the help of AtomicContributions (Version 1.3; George, 2019).

The ICOHP values were calculated for the optimized structures with the help of Lobster (Version 3.1.0; Dronskowski \& Blöchl, 1993; Deringer et al., 2011; Maintz et al., 2013, 2016). The following basis functions of the pbeVaspFit2015 basis set were used: $1 s$ for $\mathrm{H}, 2 s 2 p$ for $\mathrm{C}, \mathrm{N}$, and $\mathrm{F}$, and $5 s$ and $5 p$ for I. For all three compounds, the charge spilling was below $1.5 \%$, which indicates a very reliable projection.

\section{Conclusions}

Experimental electron-density studies on compounds with short intermolecular $\mathrm{Cl} \cdots \mathrm{Cl}$ contacts are in agreement with the commonly accepted $\sigma$-hole theory. The nucleophile, the electrophile with the $\sigma$ hole and its covalently bonded partner atom giving rise to this positive region are arranged in a linear fashion. Longer $\mathrm{Cl} \cdots \mathrm{Cl}$ distances are associated with low electron density in the bcp; only little, if any, information about the nature and strength of the interaction can be extracted. Short $\mathrm{Cl} \cdots \mathrm{Cl}$ contacts are associated with clear 
features in the electron density and derived properties, such as the Laplacian or the ESP: the charge depletion on the electrophile and the polarization of the nucleophile may be perceived, and the electron density in the bcp of the interchlorine contact increases for shorter distances.

For interactions between I atoms and small electronegative partners $D$ (such as $\mathrm{N}$ or $\mathrm{O}$ ), only a few charge-density studies have been conducted. The small number of experimental observations does not allow a simple trend to be established for the electron density in the bcp as a function of interatomic distance but rather suggests that three cases can be distinguished. (a) Our compound $\mathbf{1}$, with its very short $\mathrm{I} \cdots \mathrm{N}$ interactions of less than $2.7 \AA$, shows a rather symmetric electronic situation of the heavy halogen and resembles a three-centre-four-electron bond. The MM description suggests a higher electron density in the bcp of the I $\cdots D$ interaction than the IAM. The absolute value of electron density in the bcp exceeds that of published halogen bonds and is similar to coordinative bonds between a large cation and a small nucleophile. (b) Significantly longer and presumably weaker halogen bonds, with I $\cdots D$ separations of about $3 \AA$, reflect the commonly accepted $\sigma$-hole features. The electron density in their bcp is scarcely affected by details of the structure model. (c) Our compound 2 represents the first example in-between the above-mentioned categories for which the electron density has been established experimentally. Although it does not differ much from case $(a)$ with respect to the $\mathrm{I} \cdots D$ contact distance, $\mathbf{2}$ is clearly asymmetric with respect to the electron density about the heavy halogen. It still represents a very short halogen bond and its ESP matches the requirements for an electrostatically favourable interaction, but due to its vicinity to the charge depletion, the electron density in the associated bcp is rather low. More generally, we expect an analogous effect for related halogenbonded compounds in which $\rho_{\mathrm{bcp}}$ may be reduced due to its proximity to the $\sigma$ hole. With this surprising feature, we add yet a different flavour to halogen bonding! Although only a few experimental electron-density studies involving halogen bonds with iodine are available, we are tempted to make a comparison with hydrogen bonds, an interaction for which a wealth of high-resolution diffraction data exists. Based on a large number of $\mathrm{H} \cdots X(X=\mathrm{H}, \mathrm{C}, \mathrm{N}, \mathrm{O}, \mathrm{F}, \mathrm{S}, \mathrm{Cl}$ and $\pi)$ contacts, Espinosa and co-workers (Mata et al., 2010) have detected that increasing electronegativity of the acceptor $X$ leads to a more extended range of interactions of an entirely closed-shell nature. In agreement with these findings, all $\mathrm{Cl} \cdots \mathrm{Cl}$ contacts compiled in Fig. 3 follow the same trend; in contrast, very short interactions involving the less electronegative iodine are borderline cases with shared interactions. Additional experimental data on short halogen bonds between iodine and small nucleophiles will be required to confirm or disprove this analogy.

\section{Acknowledgements}

We thank Irmgard Kalf for help with the crystallization experiments and we acknowledge computational resources provided by JARA-HPC at the RWTH Aachen University (Project jara0069).

\section{Funding information}

Funding for this research was provided by: Deutsche Forschungsgemeinschaft (grant No. EN309/10, Charge density of halogen bonds and interhalogen contacts).

\section{References}

Abramov, Y. A. (1997). Acta Cryst. A53, 264-272.

Archer, E. M. (1948). Acta Cryst. 1, 64-69.

Bader, R. F. W. (1990). In Atoms in Molecules - A Quantum Theory. Oxford University Press.

Becke, A. D. (1993). J. Chem. Phys. 98, 5648-5652.

Bianchi, R., Forni, A. \& Pilati, T. (2003). Chem. Eur. J. 9, 1631-1638. Bianchi, R., Forni, A. \& Pilati, T. (2004). Acta Cryst. B60, 559-568.

Blessing, R. H. (1995). Acta Cryst. A51, 33-38.

Blöchl, P. E. (1994). Phys. Rev. B, 50, 17953-17979.

Bolte, M. (2004). CCDC 232560: CSD Communication, doi: 10.5517/ cc7szyx.

Bondi, A. (1964). J. Phys. Chem. 68, 441-451.

Borgen, B., Hassel, O. \& Römming, C. (1962). Acta Chem. Scand. 16, 2469-2470.

Brinck, T., Murray, J. S. \& Politzer, P. (1992). Int. J. Quantum Chem. 44 (Suppl. 19), 57-64.

Brinck, T., Murray, J. S. \& Politzer, P. (1993). Int. J. Quantum Chem. 48 (Suppl. 20), 73-88.

Bui, T. T. T., Dahaoui, S., Lecomte, C., Desiraju, G. R. \& Espinosa, E. (2009). Angew. Chem. Int. Ed. 48, 3838-3841.

Cavallo, G., Metrangolo, P., Milani, R., Pilati, T., Priimagi, A., Resnati, G. \& Terraneo, G. (2016). Chem. Rev. 116, 2478-2601.

Cinčić, D., Friščić, T. \& Jones, W. (2008). Chem. Eur. J. 14, 747-753.

Coppens, P. (1977). Isr. J. Chem. 16, 144-148.

Coppens, P. (1997). In X-ray Charge Densities and Chemical Bonding. Oxford University Press.

Cordero, B., Gómez, V., Platero-Prats, A. E., Revés, M., Echeverría, J., Cremades, E., Barragán, F. \& Alvarez, S. (2008). Dalton Trans. pp. 2832-2838.

Cremer, D. \& Kraka, E. (1984). Angew. Chem. Int. Ed. Engl. 23, 627628.

Deringer, V. L., Englert, U. \& Dronskowski, R. (2014). Chem. Commun. 50, 11547-11549.

Deringer, V. L., George, J., Dronskowski, R. \& Englert, U. (2017). Acc. Chem. Res. 50, 1231-1239.

Deringer, V. L., Tchougréeff, A. L. \& Dronskowski, R. (2011). J. Phys. Chem. A, 115, 5461-5466.

Desiraju, G. R. (1995). Angew. Chem. Int. Ed. Engl. 34, 2311-2327.

Dronskowski, R. \& Blöchl, P. E. (1993). J. Phys. Chem. 97, 8617-8624.

Espinosa, E., Alkorta, I., Elguero, J. \& Molins, E. (2002). J. Chem. Phys. 117, 5529-5542.

Espinosa, E., Lecomte, C. \& Molins, E. (1999). Chem. Phys. Lett. 300, 745-748.

Espinosa, E., Molins, E. \& Lecomte, C. (1998). Chem. Phys. Lett. 285, 170-173.

Ford, M. C. \& Ho, P. S. (2016). J. Med. Chem. 59, 1655-1670.

Frisch, M. J., et al. (2009). GAUSSIAN09. Gaussian Inc., Wallingford, CT, USA. http://www.gaussian.com.

George, J. (2019). JaGeo/Atomic Contributions: AtomicContributions. Version 1.3. http://doi.org/10.5281/zenodo.2597239.

George, J., Deringer, V. L. \& Dronskowski, R. (2014). J. Phys. Chem. $A$, 118, 3193-3200.

George, J. \& Dronskowski, R. (2017). J. Phys. Chem. A, 121, 13811387.

George, J., Wang, R., Englert, U. \& Dronskowski, R. (2017). J. Chem. Phys. 147, 074112. 
Gillespie, R. J. \& Popelier, P. L. A. (2001). In Chemical Bonding and Molecular Geometry. Oxford University Press.

Grimme, S., Antony, J., Ehrlich, S. \& Krieg, H. (2010). J. Chem. Phys. 132, 154104.

Grimme, S., Ehrlich, S. \& Goerigk, L. (2011). J. Comput. Chem. 32, $1456-1465$.

Groom, C. R., Bruno, I. J., Lightfoot, M. P. \& Ward, S. C. (2016). Acta Cryst. B72, 171-179.

Hansen, N. K. \& Coppens, P. (1978). Acta Cryst. A34, 909-921.

Hassel, O. (1970). Science, 170, 497-502.

Hathwar, V. R. \& Guru Row, T. N. (2010). J. Phys. Chem. A, 114, 13434-13441.

Hirshfeld, F. L. (1976). Acta Cryst. A32, 239-244.

Hübschle, C. B. \& Dittrich, B. (2011). J. Appl. Cryst. 44, 238-240.

IUPAC (1997). Compendium of Chemical Terminology, 2nd ed. (the 'Gold Book'), compiled by A. D. McNaught \& A. Wilkinson. Oxford: Blackwell Scientific Publications.

Kamiński, R., Domagala, S., Jarzembska, K. N., Hoser, A. A., Sanjuan-Szklarz, W. F., Gutmann, M. J., Makal, A., Malinska, M., Bak, J. M. \& Wozniak, K. (2014). Acta Cryst. A70, 72-91.

Keith, T. A. (2017). AIMAll. Version 17.01.25. TK Gristmill Software, Overland Park KS, USA.

Kieltsch, I., Eisenberger, P. \& Togni, A. (2007). Angew. Chem. Int. Ed. 46, 754-757.

Kirshenboim, O. \& Kozuch, S. (2016). J. Phys. Chem. A, 120, 94319445.

Koziskova, J., Hahn, F., Richter, J. \& Kožíšek, J. (2016). Acta Chim. Slov. 9, 136-140.

Kremer, M. \& Englert, U. (2018). Z. Kristallogr. 233, 437-452.

Kresse, G. \& Furthmüller, J. (1996). Phys. Rev. B, 54, 11169-11186.

Kresse, G. \& Hafner, J. (1993). Phys. Rev. B, 47, 558-561.

Kresse, G. \& Hafner, J. (1994). Phys. Rev. B, 49, 14251-14269.

Kresse, G. \& Joubert, D. (1999). Phys. Rev. B, 59, 1758-1775.

Lee, C., Yang, W. \& Parr, R. G. (1998). Phys. Rev. B37, 785-789.

Maintz, S., Deringer, V. L., Tchougréeff, A. L. \& Dronskowski, R. (2013). J. Comput. Chem. 34, 2557-2567.

Maintz, S., Deringer, V. L., Tchougréeff, A. L. \& Dronskowski, R. (2016). J. Comput. Chem. 37, 1030-1035.

Mata, I., Alkorta, I., Molins, E. \& Espinosa, E. (2010). Chem. Eur. J. 16, 2442-2452.

Merkens, C., Pan, F. \& Englert, U. (2013). CrystEngComm, 15, $8153-$ 8158.

Metrangolo, P. \& Resnati, G. (2001). Chem. Eur. J. 7, 2511-2519.

Nyburg, S. C. \& Faerman, C. H. (1985). Acta Cryst. B41, 274-279.

Pearson, R. G. (1963). J. Am. Chem. Soc. 85, 3533-3539.

Perdew, J. P., Burke, K. \& Ernzerhof, M. (1996). Phys. Rev. Lett. 77, 3865-3868.

Politzer, P., Murray, J. S., Clark, T. \& Resnati, G. (2017). Phys. Chem. Chem. Phys. 19, 32166-32178.

Roper, L. C., Präsang, C., Kozhevnikov, V. N., Whitwood, A. C., Karadakov, P. B. \& Bruce, D. W. (2010). Cryst. Growth Des. 10, 3710-3720.

Sakurai, T., Sundaralingam, M. \& Jeffrey, G. A. (1963). Acta Cryst. 16, 354-363.
Sala, O., Lüthi, H. P. \& Togni, A. (2014). J. Comput. Chem. 35, 21222131.

Sala, O., Lüthi, H. P., Togni, A., Iannuzzi, M. \& Hutter, J. (2015). J. Comput. Chem. 36, 785-794.

Schreurs, A. M. M. (2004). MERGEHKLF5. Utrecht University, The Netherlands.

Seppelt, K., Bläser, D., Ellern, A., Antipin, M. Y., Boese, A. D. \& Boese, R. (2004). Angew. Chem. Int. Ed. Engl. 36, 1489-1492.

Serb, M.-D., Merkens, C., Kalf, I. \& Englert, U. (2015). Acta Cryst. C71, 991-995.

Serb, M.-D., Wang, R., Meven, M. \& Englert, U. (2011). Acta Cryst. B67, 552-559.

Sheldrick, G. M. (2008). Acta Cryst. A64, 112-122.

Sheldrick, G. M. (2015). Acta Cryst. C71, 3-8.

Smith, D. G. A., Burns, L. A., Patkowski, K. \& Sherrill, C. D. (2016). J. Phys. Chem. Lett. 7, 2197-2203.

Sørensen, H. O., Stewart, R. F., McIntyre, G. J. \& Larsen, S. (2003). Acta Cryst. A59, 540-550.

Spek, A. L. (2009). Acta Cryst. D65, 148-155.

Stephens, P. J., Devlin, F. J., Chabalowski, C. F. \& Frisch, M. J. (1994). J. Phys. Chem. 98, 11623-11627.

Stoe \& Cie (2017). $X$-AREA. Stoe \& Cie, Darmstadt, Germany.

Syssa-Magalé, J. L., Boubekeur, K., Leroy, J., Chamoreau, L. M., Fave, C. \& Schöllhorn, B. (2014). CrystEngComm, 16, 1038010384.

Thompson, J. D., Winget, P. \& Truhlar, D. G. (2001). PhysChemComm, 4, 72-77.

Togo, A., Oba, F. \& Tanaka, I. (2008). Phys. Rev. B, 78, 134106.

Togo, A. \& Tanaka, I. (2015). Scr. Mater. 108, 1-5.

Tsirelson, V. G., Zhou, P. F., Tang, T.-H. \& Bader, R. F. W. (1995). Acta Cryst. A51, 143-153.

Volkov, A., Gatti, C., Abramov, Y. \& Coppens, P. (2000). Acta Cryst. A56, 252-258.

Volkov, A., Macchi, P., Farrugia, L. J., Gatti, C., Mallinson, P., Richter, T. \& Koritsanszky, T. (2006). XD2006. State University of New York, Buffalo, NY, USA.

Vosko, S. H., Wilk, L. \& Nusair, M. (1980). Can. J. Phys. 58, 12001211.

Wang, A. \& Englert, U. (2017). Acta Cryst. C73, 803-809.

Wang, A., Wang, R., Kalf, I., Dreier, A., Lehmann, C. W. \& Englert, U. (2017). Cryst. Growth Des. 17, 2357-2364.

Wang, R., Dols, T. S., Lehmann, C. W. \& Englert, U. (2012). Chem. Commun. 48, 6830-6832.

Wang, R., Dols, T. S., Lehmann, C. W. \& Englert, U. (2013). Z. Anorg. Allg. Chem. 639, 1933-1939.

Wang, R., Hartnick, D. \& Englert, U. (2018a). Z. Kristallogr. 233, $733-$ 744.

Wang, R., Kalf, I. \& Englert, U. (2018b). RSC Adv. 8, 3428734290.

Wang, R., Lehmann, C. W. \& Englert, U. (2009). Acta Cryst. B65, 600611.

Wolters, L. P., Schyman, P., Pavan, M. J., Jorgensen, W. L., Bickelhaupt, F. M. \& Kozuch, S. (2014). WIREs Comput. Mol. Sci. 4, 523-540. 


\section{supporting information}

Acta Cryst. (2019). C75, 1190-1201 [https://doi.org/10.1107/S205322961901132X]

\section{The many flavours of halogen bonds - message from experimental electron density and Raman spectroscopy}

\section{Ruimin Wang, Janine George, Shannon Kimberly Potts, Marius Kremer, Richard Dronskowski and Ulli Englert}

Computing details

Data collection: $X$-AREA (Stoe \& Cie, 2017); cell refinement: $X$-AREA (Stoe \& Cie, 2017); data reduction: $X$-AREA (Stoe \& Cie, 2017); program(s) used to solve structure: SHELXS97 (Sheldrick, 2008); program(s) used to refine structure: SHELXL2018 (Sheldrick, 2015); software used to prepare material for publication: SHELXL2018 (Sheldrick, 2015) and PLATON (Spek, 2009).

1,4-Diazabicyclo[2.2.2] octane 1,2,4,5-tetrafluoro-3,6-diiodobenzene

Crystal data

$\mathrm{C}_{6} \mathrm{H}_{12} \mathrm{~N}_{2} \cdot \mathrm{C}_{6} \mathrm{~F}_{4} \mathrm{I}_{2}$

$M_{r}=514.04$

Triclinic, $P \overline{1}$

$a=6.77971(9) \AA$

$b=10.82624(17) \AA$

$c=11.36217(17) \AA$

$\alpha=107.3260(12)^{\circ}$

$\beta=92.9637(12)^{\circ}$

$\gamma=104.7718(12)^{\circ}$

$V=762.42(2) \AA^{3}$

\section{Data collection}

Stoe \& Cie Stadivari goniometer with Pilatus 200k area detector diffractometer

Radiation source: XENOCS microsource fine slice $\omega /$ phi scans Absorption correction: multi-scan

(X-AREA; Stoe \& Cie, 2017)

$T_{\min }=0.245, T_{\max }=0.691$

\section{Refinement}

Refinement on $F^{2}$

Least-squares matrix: full

$R\left[F^{2}>2 \sigma\left(F^{2}\right)\right]=0.018$

$w R\left(F^{2}\right)=0.034$

$S=1.00$

12807 reflections

181 parameters
$Z=2$

$F(000)=480$

$D_{\mathrm{x}}=2.239 \mathrm{Mg} \mathrm{m}^{-3}$

Mo $K \alpha$ radiation, $\lambda=0.71073 \AA$

Cell parameters from 66670 reflections

$\theta=3.1-56.7^{\circ}$

$\mu=4.16 \mathrm{~mm}^{-1}$

$T=100 \mathrm{~K}$

Rod, colourless

$0.27 \times 0.07 \times 0.03 \mathrm{~mm}$

143675 measured reflections 12807 independent reflections 9751 reflections with $I>2 \sigma(I)$

$R_{\text {int }}=0.049$

$\theta_{\text {max }}=45.5^{\circ}, \theta_{\min }=3.1^{\circ}$

$h=-13 \rightarrow 11$

$k=-21 \rightarrow 19$

$l=-22 \rightarrow 22$

0 restraints

Primary atom site location: other

Hydrogen site location: inferred from neighbouring sites

$\mathrm{H}$-atom parameters constrained

$w=1 /\left[\sigma^{2}\left(F_{\mathrm{o}}^{2}\right)+(0.010 P)^{2}\right]$

where $P=\left(F_{\mathrm{o}}^{2}+2 F_{\mathrm{c}}^{2}\right) / 3$ 
$(\Delta / \sigma)_{\max }=0.004$

$\Delta \rho_{\min }=-1.16$ e $\AA^{-3}$

$\Delta \rho_{\max }=0.80$ e $\AA^{-3}$

Special details

Geometry. All esds (except the esd in the dihedral angle between two 1.s. planes) are estimated using the full covariance matrix. The cell esds are taken into account individually in the estimation of esds in distances, angles and torsion angles; correlations between esds in cell parameters are only used when they are defined by crystal symmetry. An approximate (isotropic) treatment of cell esds is used for estimating esds involving l.s. planes.

Fractional atomic coordinates and isotropic or equivalent isotropic displacement parameters $\left(\AA^{2}\right)$

\begin{tabular}{lllll}
\hline & $x$ & $y$ & $z$ & $U_{\text {iso }} / U_{\text {eq }}$ \\
\hline I1 & $0.74992(2)$ & $0.44294(2)$ & $0.73025(2)$ & $0.01419(1)$ \\
I2 & $-0.21394(2)$ & $0.02101(2)$ & $0.76680(2)$ & $0.01425(1)$ \\
F1 & $0.56848(10)$ & $0.33142(7)$ & $0.94934(6)$ & $0.02165(13)$ \\
F2 & $0.20436(10)$ & $0.17534(7)$ & $0.96410(6)$ & $0.01974(12)$ \\
F3 & $-0.02960(9)$ & $0.13259(7)$ & $0.54999(6)$ & $0.01925(12)$ \\
F4 & $0.33841(10)$ & $0.28257(7)$ & $0.53305(6)$ & $0.01955(12)$ \\
C1 & $0.46685(13)$ & $0.30993(9)$ & $0.73975(9)$ & $0.01342(13)$ \\
C2 & $0.42373(14)$ & $0.28095(10)$ & $0.84823(9)$ & $0.01438(14)$ \\
C3 & $0.23323(14)$ & $0.20125(10)$ & $0.85630(9)$ & $0.01370(14)$ \\
C4 & $0.07458(13)$ & $0.14789(9)$ & $0.75719(9)$ & $0.01325(13)$ \\
C5 & $0.11721(13)$ & $0.17809(10)$ & $0.64914(9)$ & $0.01386(14)$ \\
C6 & $0.30893(14)$ & $0.25608(10)$ & $0.64064(9)$ & $0.01389(14)$ \\
N1 & $1.09790(12)$ & $0.63911(8)$ & $0.73269(8)$ & $0.01400(12)$ \\
N2 & $1.42176(12)$ & $0.83481(8)$ & $0.76067(8)$ & $0.01385(12)$ \\
C11 & $1.28182(15)$ & $0.59002(10)$ & $0.72641(10)$ & $0.01748(16)$ \\
H11A & 1.268019 & 0.518567 & 0.645681 & $0.021^{*}$ \\
H11B & 1.294608 & 0.550661 & 0.793725 & $0.021^{*}$ \\
C12 & $1.47710(14)$ & $0.70798(10)$ & $0.74035(10)$ & $0.01605(15)$ \\
H12A & 1.576140 & 0.716864 & 0.811608 & $0.019^{*}$ \\
H12B & 1.544109 & 0.688766 & 0.664188 & $0.019^{*}$ \\
C13 & $1.08371(14)$ & $0.70048(10)$ & $0.63386(9)$ & $0.01701(16)$ \\
H13A & 0.958752 & 0.732077 & 0.636187 & $0.020^{*}$ \\
H13B & 1.072396 & 0.632196 & 0.551475 & $0.020^{*}$ \\
C14 & $1.27738(15)$ & $0.82117(10)$ & $0.65248(10)$ & $0.01608(15)$ \\
H14A & 1.346068 & 0.806440 & 0.576759 & $0.019^{*}$ \\
H14B & 1.236124 & 0.905226 & 0.666324 & $0.019^{*}$ \\
C15 & $1.11921(15)$ & $0.74392(10)$ & $0.85444(9)$ & $0.01706(15)$ \\
H15A & 1.123961 & 0.703843 & 0.921935 & $0.020^{*}$ \\
H15B & 0.998469 & 0.779927 & 0.858430 & $0.020^{*}$ \\
C16 & $1.31888(15)$ & $0.86012(10)$ & $0.87293(9)$ & $0.01679(15)$ \\
H16A & 1.284657 & 0.946783 & 0.889403 & $0.020^{*}$ \\
H16B & 1.412728 & 0.866653 & 0.945634 & $0.020^{*}$ \\
& & & &
\end{tabular}

Atomic displacement parameters $\left(\AA^{2}\right)$

\begin{tabular}{lllllll}
\hline & $U^{11}$ & $U^{22}$ & $U^{33}$ & $U^{12}$ & $U^{13}$ & $U^{23}$ \\
\hline I1 & $0.00990(2)$ & $0.01442(2)$ & $0.01698(3)$ & $0.00031(2)$ & $0.00196(2)$ & $0.00583(2)$
\end{tabular}




\begin{tabular}{lllllll} 
I2 & $0.01023(2)$ & $0.01437(2)$ & $0.01675(3)$ & $0.00002(2)$ & $0.00187(2)$ & $0.00592(2)$ \\
F1 & $0.0145(2)$ & $0.0290(3)$ & $0.0166(3)$ & $-0.0029(2)$ & $-0.0049(2)$ & $0.0091(2)$ \\
F2 & $0.0178(3)$ & $0.0271(3)$ & $0.0143(3)$ & $0.0010(2)$ & $0.0027(2)$ & $0.0111(2)$ \\
F3 & $0.0148(2)$ & $0.0224(3)$ & $0.0160(3)$ & $-0.0021(2)$ & $-0.00489(19)$ & $0.0069(2)$ \\
F4 & $0.0182(3)$ & $0.0245(3)$ & $0.0144(3)$ & $-0.0004(2)$ & $0.0019(2)$ & $0.0096(2)$ \\
C1 & $0.0106(3)$ & $0.0136(3)$ & $0.0150(4)$ & $0.0007(3)$ & $0.0014(2)$ & $0.0054(3)$ \\
C2 & $0.0113(3)$ & $0.0165(4)$ & $0.0134(4)$ & $0.0005(3)$ & $-0.0008(2)$ & $0.0054(3)$ \\
C3 & $0.0125(3)$ & $0.0154(3)$ & $0.0124(3)$ & $0.0012(3)$ & $0.0011(2)$ & $0.0057(3)$ \\
C4 & $0.0107(3)$ & $0.0130(3)$ & $0.0146(4)$ & $0.0005(3)$ & $0.0013(2)$ & $0.0049(3)$ \\
C5 & $0.0114(3)$ & $0.0145(3)$ & $0.0136(4)$ & $0.0005(3)$ & $-0.0005(2)$ & $0.0046(3)$ \\
C6 & $0.0132(3)$ & $0.0147(3)$ & $0.0131(4)$ & $0.0014(3)$ & $0.0017(2)$ & $0.0057(3)$ \\
N1 & $0.0110(3)$ & $0.0141(3)$ & $0.0147(3)$ & $0.0005(2)$ & $0.0010(2)$ & $0.0042(2)$ \\
N2 & $0.0108(3)$ & $0.0137(3)$ & $0.0155(3)$ & $0.0003(2)$ & $0.0000(2)$ & $0.0055(2)$ \\
C11 & $0.0144(3)$ & $0.0143(3)$ & $0.0235(5)$ & $0.0031(3)$ & $0.0029(3)$ & $0.0064(3)$ \\
C12 & $0.0116(3)$ & $0.0170(4)$ & $0.0203(4)$ & $0.0037(3)$ & $0.0026(3)$ & $0.0074(3)$ \\
C13 & $0.0132(3)$ & $0.0198(4)$ & $0.0147(4)$ & $-0.0002(3)$ & $-0.0019(3)$ & $0.0056(3)$ \\
C14 & $0.0141(3)$ & $0.0162(4)$ & $0.0175(4)$ & $0.0010(3)$ & $-0.0001(3)$ & $0.0079(3)$ \\
C15 & $0.0143(3)$ & $0.0191(4)$ & $0.0153(4)$ & $0.0016(3)$ & $0.0037(3)$ & $0.0043(3)$ \\
C16 & $0.0165(4)$ & $0.0141(3)$ & $0.0154(4)$ & $0.0004(3)$ & $0.0009(3)$ & $0.0021(3)$ \\
& & & & & & \\
\hline
\end{tabular}

Geometric parameters $\left(\AA,{ }^{\circ}\right)$

\begin{tabular}{llll}
\hline $\mathrm{I} 1-\mathrm{C} 1$ & $2.1149(9)$ & $\mathrm{N} 2-\mathrm{C} 14$ & $1.4781(12)$ \\
$\mathrm{I} 2-\mathrm{C} 4$ & $2.1133(9)$ & $\mathrm{C} 11-\mathrm{C} 12$ & $1.5507(13)$ \\
$\mathrm{F} 1-\mathrm{C} 2$ & $1.3482(11)$ & $\mathrm{C} 11-\mathrm{H} 11 \mathrm{~A}$ & 0.9900 \\
$\mathrm{~F} 2-\mathrm{C} 3$ & $1.3487(11)$ & $\mathrm{C} 11-\mathrm{H} 11 \mathrm{~B}$ & 0.9900 \\
$\mathrm{~F} 3-\mathrm{C} 5$ & $1.3439(11)$ & $\mathrm{C} 12-\mathrm{H} 12 \mathrm{~A}$ & 0.9900 \\
$\mathrm{~F} 4-\mathrm{C} 6$ & $1.3496(11)$ & $\mathrm{C} 12-\mathrm{H} 12 \mathrm{~B}$ & 0.9900 \\
$\mathrm{C} 1-\mathrm{C} 6$ & $1.3858(13)$ & $\mathrm{C} 13-\mathrm{C} 14$ & $1.5517(13)$ \\
$\mathrm{C} 1-\mathrm{C} 2$ & $1.3870(13)$ & $\mathrm{C} 13-\mathrm{H} 13 \mathrm{~A}$ & 0.9900 \\
$\mathrm{C} 2-\mathrm{C} 3$ & $1.3828(13)$ & $\mathrm{C} 13-\mathrm{H} 13 \mathrm{~B}$ & 0.9900 \\
$\mathrm{C} 3-\mathrm{C} 4$ & $1.3889(13)$ & $\mathrm{C} 14-\mathrm{H} 14 \mathrm{~A}$ & 0.9900 \\
$\mathrm{C} 4-\mathrm{C} 5$ & $1.3875(13)$ & $\mathrm{C} 14-\mathrm{H} 14 \mathrm{~B}$ & 0.9900 \\
$\mathrm{C} 5-\mathrm{C} 6$ & $1.3833(13)$ & $\mathrm{C} 15-\mathrm{C} 16$ & $1.5505(13)$ \\
$\mathrm{N} 1-\mathrm{C} 11$ & $1.4721(13)$ & $\mathrm{C} 15-\mathrm{H} 15 \mathrm{~A}$ & 0.9900 \\
$\mathrm{~N} 1-\mathrm{C} 13$ & $1.4756(13)$ & $\mathrm{C} 15-\mathrm{H} 15 \mathrm{~B}$ & 0.9900 \\
$\mathrm{~N} 1-\mathrm{C} 15$ & $1.4775(13)$ & $\mathrm{C} 16-\mathrm{H} 16 \mathrm{~A}$ & 0.9900 \\
$\mathrm{~N} 2-\mathrm{C} 12$ & $1.4705(13)$ & $\mathrm{C} 16-\mathrm{H} 16 \mathrm{~B}$ & 0.9900 \\
$\mathrm{~N} 2-\mathrm{C} 16$ & $1.4731(13)$ & & $110.18(7)$ \\
& & & 109.6 \\
$\mathrm{C} 6-\mathrm{C} 1-\mathrm{C} 2$ & $116.62(8)$ & $\mathrm{N} 2-\mathrm{C} 12-\mathrm{C} 11$ & 109.6 \\
$\mathrm{C} 6-\mathrm{C} 1-\mathrm{I} 1$ & $121.34(7)$ & $\mathrm{N} 2-\mathrm{C} 12-\mathrm{H} 12 \mathrm{~A}$ & 109.6 \\
$\mathrm{C} 2-\mathrm{C} 1-\mathrm{I} 1$ & $121.84(7)$ & $\mathrm{C} 11-\mathrm{C} 12-\mathrm{H} 12 \mathrm{~A}$ & 109.6 \\
$\mathrm{~F} 1-\mathrm{C} 2-\mathrm{C} 3$ & $118.35(8)$ & $\mathrm{N} 2-\mathrm{C} 12-\mathrm{H} 12 \mathrm{~B}$ & 108.1 \\
$\mathrm{~F} 1-\mathrm{C} 2-\mathrm{C} 1$ & $120.13(8)$ & $\mathrm{C} 11-\mathrm{C} 12-\mathrm{H} 12 \mathrm{~B}$ & $110.08(8)$ \\
$\mathrm{C} 3-\mathrm{C} 2-\mathrm{C} 1$ & $121.52(8)$ & $\mathrm{H} 12 \mathrm{C} 12-\mathrm{H} 12 \mathrm{~B}$ & 109.6 \\
$\mathrm{~F} 2-\mathrm{C} 3-\mathrm{C} 2$ & $118.05(8)$ & $\mathrm{N} 1-\mathrm{C} 13-\mathrm{C} 14$ & \\
$\mathrm{~F} 2-\mathrm{C} 3-\mathrm{C} 4$ & $120.09(8)$ & $\mathrm{N} 1-\mathrm{C} 13-\mathrm{H} 13 \mathrm{~A}$ & \\
& & &
\end{tabular}




$\begin{array}{ll}\mathrm{C} 2-\mathrm{C} 3-\mathrm{C} 4 & 121.86(9) \\ \mathrm{C} 5-\mathrm{C} 4-\mathrm{C} 3 & 116.57(8) \\ \mathrm{C} 5-\mathrm{C} 4-\mathrm{I} 2 & 121.29(7) \\ \mathrm{C} 3-\mathrm{C} 4-\mathrm{I} 2 & 122.11(7) \\ \text { F3-C5-C6 } & 118.37(8) \\ \text { F3-C5-C4 } & 120.16(8) \\ \text { C6-C5-C4 } & 121.46(9) \\ \text { F4-C6-C5 } & 118.15(8) \\ \text { F4-C6-C1 } & 119.87(8) \\ \text { C5-C6-C1 } & 121.96(9) \\ \text { C11-N1-C13 } & 109.05(8) \\ \text { C11-N1-C15 } & 109.01(8) \\ \text { C13-N1-C15 } & 108.43(8) \\ \text { C12-N2-C16 } & 108.72(8) \\ \text { C12-N2-C14 } & 109.06(8) \\ \text { C16-N2-C14 } & 108.95(8) \\ \text { N1-C11-C12 } & 110.01(8) \\ \text { N1-C11-H11A } & 109.7 \\ \text { C12-C11-H11A } & 109.7 \\ \text { N1-C11-H11B } & 109.7 \\ \text { C12-C11-H11B } & 109.7 \\ \text { H11A-C11-H11B } & 108.2 \\ \text { C6-C1-C2-F1 } & \\ \text { I1-C1-C2-F1 } & -178.98(9) \\ \text { C6-C1-C2-C3 } & -4.06(13) \\ \text { I1-C1-C2-C3 } & 0.60(14) \\ \text { F1-C2-C3-F2 } & 175.51(7) \\ \text { C1-C2-C3-F2 } & -1.74(14) \\ \text { F1-C2-C3-C4 } & 178.68(9) \\ \text { C1-C2-C3-C4 } & 178.59(9) \\ \text { F2-C3-C4-C5 } & -0.99(15) \\ \text { C2-C3-C4-C5 } & -179.37(9) \\ \text { F2-C3-C4-I2 } & 0.30(14) \\ \text { C2-C3-C4-I2 } & -1.62(13) \\ \text { C3-C4-C5-F3 } & 178.04(7) \\ \text { I2-C4-C5-F3 } & -178.60(9) \\ \text { C3-C4-C5-C6 } & 3.64(13) \\ \text { I2-C4-C5-C6 } & 0.74(14) \\ \text { F3-C5-C6-F4 } & -177.02(7) \\ \text { C4-C5-C6-F4 } & 0.09(14) \\ \text { F3-C5-C6-C1 } & -179.26(9) \\ \text { C4-C5-C6-C1 } & \\ & \end{array}$

\begin{tabular}{|c|c|}
\hline $\mathrm{C} 14-\mathrm{C} 13-\mathrm{H} 13 \mathrm{~A}$ & 109.6 \\
\hline $\mathrm{N} 1-\mathrm{C} 13-\mathrm{H} 13 \mathrm{~B}$ & 109.6 \\
\hline $\mathrm{C} 14-\mathrm{C} 13-\mathrm{H} 13 \mathrm{~B}$ & 109.6 \\
\hline $\mathrm{H} 13 \mathrm{~A}-\mathrm{C} 13-\mathrm{H} 13 \mathrm{~B}$ & 108.2 \\
\hline $\mathrm{N} 2-\mathrm{C} 14-\mathrm{C} 13$ & $109.91(8)$ \\
\hline $\mathrm{N} 2-\mathrm{C} 14-\mathrm{H} 14 \mathrm{~A}$ & 109.7 \\
\hline $\mathrm{C} 13-\mathrm{C} 14-\mathrm{H} 14 \mathrm{~A}$ & 109.7 \\
\hline $\mathrm{N} 2-\mathrm{C} 14-\mathrm{H} 14 \mathrm{~B}$ & 109.7 \\
\hline $\mathrm{C} 13-\mathrm{C} 14-\mathrm{H} 14 \mathrm{~B}$ & 109.7 \\
\hline $\mathrm{H} 14 \mathrm{~A}-\mathrm{C} 14-\mathrm{H} 14 \mathrm{~B}$ & 108.2 \\
\hline $\mathrm{N} 1-\mathrm{C} 15-\mathrm{C} 16$ & $110.12(8)$ \\
\hline $\mathrm{N} 1-\mathrm{C} 15-\mathrm{H} 15 \mathrm{~A}$ & 109.6 \\
\hline $\mathrm{C} 16-\mathrm{C} 15-\mathrm{H} 15 \mathrm{~A}$ & 109.6 \\
\hline $\mathrm{N} 1-\mathrm{C} 15-\mathrm{H} 15 \mathrm{~B}$ & 109.6 \\
\hline $\mathrm{C} 16-\mathrm{C} 15-\mathrm{H} 15 \mathrm{~B}$ & 109.6 \\
\hline $\mathrm{H} 15 \mathrm{~A}-\mathrm{C} 15-\mathrm{H} 15 \mathrm{~B}$ & 108.2 \\
\hline $\mathrm{N} 2-\mathrm{C} 16-\mathrm{C} 15$ & $109.95(8)$ \\
\hline $\mathrm{N} 2-\mathrm{C} 16-\mathrm{H} 16 \mathrm{~A}$ & 109.7 \\
\hline $\mathrm{C} 15-\mathrm{C} 16-\mathrm{H} 16 \mathrm{~A}$ & 109.7 \\
\hline $\mathrm{N} 2-\mathrm{C} 16-\mathrm{H} 16 \mathrm{~B}$ & 109.7 \\
\hline $\mathrm{C} 15-\mathrm{C} 16-\mathrm{H} 16 \mathrm{~B}$ & 109.7 \\
\hline $\mathrm{H} 16 \mathrm{~A}-\mathrm{C} 16-\mathrm{H} 16 \mathrm{~B}$ & 108.2 \\
\hline $\mathrm{C} 2-\mathrm{C} 1-\mathrm{C} 6-\mathrm{F} 4$ & $178.53(9)$ \\
\hline $\mathrm{I} 1-\mathrm{C} 1-\mathrm{C} 6-\mathrm{F} 4$ & $3.59(13)$ \\
\hline $\mathrm{C} 2-\mathrm{C} 1-\mathrm{C} 6-\mathrm{C} 5$ & $0.45(14)$ \\
\hline $\mathrm{I} 1-\mathrm{C} 1-\mathrm{C} 6-\mathrm{C} 5$ & $-174.50(7)$ \\
\hline $\mathrm{C} 13-\mathrm{N} 1-\mathrm{C} 11-\mathrm{C} 12$ & $57.93(10)$ \\
\hline $\mathrm{C} 15-\mathrm{N} 1-\mathrm{C} 11-\mathrm{C} 12$ & $-60.28(10)$ \\
\hline $\mathrm{C} 16-\mathrm{N} 2-\mathrm{C} 12-\mathrm{C} 11$ & $58.21(10)$ \\
\hline $\mathrm{C} 14-\mathrm{N} 2-\mathrm{C} 12-\mathrm{C} 11$ & $-60.47(10)$ \\
\hline $\mathrm{N} 1-\mathrm{C} 11-\mathrm{C} 12-\mathrm{N} 2$ & $2.24(12)$ \\
\hline $\mathrm{C} 11-\mathrm{N} 1-\mathrm{C} 13-\mathrm{C} 14$ & $-60.50(10)$ \\
\hline $\mathrm{C} 15-\mathrm{N} 1-\mathrm{C} 13-\mathrm{C} 14$ & $58.07(10)$ \\
\hline $\mathrm{C} 12-\mathrm{N} 2-\mathrm{C} 14-\mathrm{C} 13$ & $57.77(10)$ \\
\hline $\mathrm{C} 16-\mathrm{N} 2-\mathrm{C} 14-\mathrm{C} 13$ & $-60.77(10)$ \\
\hline $\mathrm{N} 1-\mathrm{C} 13-\mathrm{C} 14-\mathrm{N} 2$ & $2.32(11)$ \\
\hline $\mathrm{C} 11-\mathrm{N} 1-\mathrm{C} 15-\mathrm{C} 16$ & $57.29(11)$ \\
\hline $\mathrm{C} 13-\mathrm{N} 1-\mathrm{C} 15-\mathrm{C} 16$ & $-61.30(10)$ \\
\hline $\mathrm{C} 12-\mathrm{N} 2-\mathrm{C} 16-\mathrm{C} 15$ & $-61.15(10)$ \\
\hline $\mathrm{C} 14-\mathrm{N} 2-\mathrm{C} 16-\mathrm{C} 15$ & $57.61(10)$ \\
\hline $\mathrm{N} 1-\mathrm{C} 15-\mathrm{C} 16-\mathrm{N} 2$ & $3.08(12)$ \\
\hline
\end{tabular}

